AperTO - Archivio Istituzionale Open Access dell'Università di Torino

\title{
Adult neurogenesis in mammals: A theme with many variations
}

\section{This is the author's manuscript}

Original Citation:

Availability:

This version is available http://hdl.handle.net/2318/133743

since 2016-01-12T10:13:56Z

Published version:

DOI:10.1111/j.1460-9568.2011.07832.x

Terms of use:

Open Access

Anyone can freely access the full text of works made available as "Open Access". Works made available under a Creative Commons license can be used according to the terms and conditions of said license. Use of all other works requires consent of the right holder (author or publisher) if not exempted from copyright protection by the applicable law. 


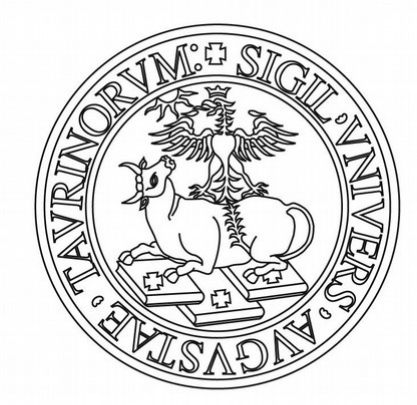

\section{UNIVERSITÀ DEGLI STUDI DI TORINO}

This is an author version of the contribution published on:

Questa è la versione dell'autore dell'opera:

[European Journal of Neuroscience, 34 (6), 2011, doi:10.1111/j.1460-9568.2011.07832.x]

ovvero [L. Bonfanti, P. Peretto, 34 (6), John Wiley \& Sons, 2011, pagg.930-950]

The definitive version is available at:

La versione definitiva è disponibile alla URL:

[http://onlinelibrary.wiley.com/doi/10.1111/j.1460-

9568.2011.07832.x/abstract] 


\title{
Adult neurogenesis in mammals - a theme with many variations
}

\author{
Luca Bonfanti ${ }^{1,2}$ and Paolo Peretto ${ }^{1,3}$ \\ ${ }^{1}$ Neuroscience Institute Cavalieri Ottolenghi (NICO), Regione Gonzole 10 - \\ 10043 Orbassano (TO), Italy \\ ${ }^{2}$ Department of Veterinary Morphophysiology, University of Turin, Turin, Italy \\ ${ }^{3}$ Department of Animal and Human Biology, University of Turin, Turin, Italy
}

Keywords: lifespan, parenchymal progenitors, postnatal development, stem cells, structural plasticity

\begin{abstract}
Investigations of adult neurogenesis in recent years have revealed numerous differences among mammalian species, reflecting the remarkable diversity in brain anatomy and function of mammals. As a mechanism of brain plasticity, adult neurogenesis might also differ due to behavioural specialization or adaptation to specific ecological niches. Because most research has focused on rodents and only limited data are available on other mammalian orders, it is hotly debated whether, in some species, adult neurogenesis also takes place outside of the well-characterized subventricular zone of the lateral ventricle and subgranular zone of the dentate gyrus. In particular, evidence for the functional integration of new neurons born in 'non-neurogenic' zones is controversial. Considering the promise of adult neurogenesis for regenerative medicine, we posit that differences in the extent, regional occurrence and completion of adult neurogenesis need to be considered from a speciesspecific perspective. In this review, we provide examples underscoring that the mechanisms of adult neurogenesis cannot simply be generalized to all mammalian species. Despite numerous similarities, there are distinct differences, notably in neuronal maturation, survival and functional integration in existing synaptic circuits, as well as in the nature and localization of neural precursor cells. We also propose a more appropriate use of terminology to better describe these differences and their relevance for brain plasticity under physiological and pathophysiological conditions. In conclusion, we emphasize the need for further analysis of adult neurogenesis in diverse mammalian species to fully grasp the spectrum of variation of this adaptative mechanism in the adult CNS.
\end{abstract}

\section{Introduction}

The discovery of adult neurogenesis in mammals (Altman, 1963; Altman \& Das, 1965) was initially largely ignored. Thirty years later, it was somehow rediscovered after more detailed characterization of the neurogenic sites in rodents (Lois \& Alvarez-Buylla, 1994; Doetsch, 2003), the isolation of neural stem cells (Reynolds \& Weiss, 1992; Gage, 2000), and the demonstration that something similar can be found in humans (Eriksson et al., 1998; Sanai et al., 2004; Curtis et al., 2007). During the last two decades, this intriguingly persisting process in the mammalian brain was intensely investigated, and

Correspondence: Dr L. Bonfanti, ${ }^{2}$ Department of Veterinary Morphophysiology, as above, and Dr P. Peretto, ${ }^{3}$ Department of Animal and Human Biology, as above. E-mail:

luca.bonfanti@unito.it; paolo.peretto@unito.it 
several review articles progressively made the point on its extension, features and significance (Emsley et al., 2005; Sohur et al., 2006; Gould, 2007;

Bonfanti \& Ponti, 2008; Migaud et al., 2010; Curtis et al., 2011).

In parallel with phylogenetic analyses directed at comparing mammals and other animal groups, differences in adult neurogenesis have been emerging even among mammals in recent years. There are several reasons for further analysis of adult mammalian neurogenesis in a comparative perspective. First of all, most studies on this topic have been carried out on rodents for many years, a fact that has led many investigators to identify rats and mice as universal models for mammals. To support this idea, the animal species on which the study was carried out are not reported in the manuscript title, and they are often just generically referred to as mammals (e.g. Zhao et al., 2003; Dayer et al., 2005; Pierce \& Xu, 2010). Nevertheless, we know that brain anatomy and physiology substantially differ in rodents and other mammals (van Dongen, 1998). More detailed exploration of adult mammalian neurogenesis has started, revealing some remarkable differences/variations (Luzzati et al., 2006; Amrein et al., 2007; Ponti et al., 2008), which involve closely related orders (e.g. rodents and lagomorphs; Luzzati et al., 2006; Ponti et al., 2008), species (e.g. rat and mouse; Magavi et al., 2000; Gould et al., 2001; Dayer et al., 2005; Peretto et al., 2005; Snyder et al., 2010) and even different strains (Kempermann et al., 2006; Schauwecker, 2006; Alahmed \& Herbert, 2008; Johnson et al., 2010; Clark et al., 2011; Epp et al., 2011). In addition to the anatomy, the adaptation to ecological pressures also remarkably vary in different mammals, making it one of the most satisfactory functional explanations for adult neurogenesis in the entire phylogenetic tree (article by Barker et al., 2011). On the whole, variations in adult neurogenesis among mammals can be linked to multiple, genetically determined variables spanning from the different brain anatomy/developmental history to the age of puberty/lifespan. Yet, this range of possibilities can be increased by nongenetic variables, such as experience-dependent cues (Johnson et al., 2010; Barker et al., 2011).

Since the first demonstration of adult neurogenesis in rodents, we have learnt that two brain regions referred to as adult neurogenic sites are primarily involved - the forebrain subventricular zone (SVZ; Lois \& Alvarez-Buylla, 1994) and the dentate gyrus of the hippocampus (subgranular zone, SGZ; Kempermann et al., 2004), both related to olfactory/learning / memory processes (Kempermann et al., 2004; Lledo et al., 2006). Apart from an intriguing deviation described in bats (Amrein et al., 2007), neurogenesis in SVZ and SGZ is substantially present in all vertebrates and mammals studied so far (Lindsey \& Tropepe, 2006).

In addition to neurogenic sites, several new areas have been reported to harbour different types of neurogenic/gliogenic processes in other CNS regions (reviewed in Sohur et al., 2006; Gould, 2007; Bonfanti \& Ponti, 2008; Migaud et al., 2010). This suggests that structural plasticity involving a de novo cell genesis in the mature mammalian brain could be more widespread than previously thought. In parallel with a new regionalization in rodents (i.e. existence/absence; Zhao et al., 2003; Dayer et al., 2005; Kokoeva et al., 2005), recent reports have also revealed remarkable differences in non-rodent mammals (Luzzati et al., 2006; Ponti et al., 2008), thus adding new elements of heterogeneity that hamper the achievement of a common, 'transversal' view of adult mammalian neurogenesis. Such heterogeneity is not just restricted to the anatomical location of adult neurogenic processes, but also involves other 
factors, for instance, neurogenesis can even be extended postnatally for different periods. Consequently, late developmental, postnatal, juvenile and persistent (life-long) neurogenesis should be examined one at a time. In addition, adult neurogenesis can occur with different rates and intensities at different brain sites of the same animal species and in the same brain region in diverse mammals. Finally, increasingly numerous reports show that the genesis of new neurons / glial cells can be induced in normally non-neurogenic regions as a consequence of altered homeostasis (Pierce \& Xu, 2010) and diverse neuropathological states (Arvidsson et al., 2002; Nakatomi et al., 2002; Ohira et al., 2010). These results introduce a further variable, linked to spontaneous vs. experimentally induced and lesion-induced neurogenesis. On the whole, it appears that different 'types' of neurogenic processes may occur in the adult mammalian CNS, depending on several aspects, including different animal species, age and physiological/pathological states. In the past, some discrepancies among different studies were ascribed to methodological aspects, at times engendering ruthless debates on the existence or absence of neurogenesis at certain locations, based on the reliability of cell proliferation detection in situ (e.g. in the cerebral cortex Gould et al., 1999; Kornack \& Rakic, 2001). Nevertheless, this is not the only limit to assessing the occurrence of adult neurogenesis. There are other misconceptions depending on the meaning generally attributed to this word. In fact, even after having unequivocally confirmed the occurrence of cell proliferation within a CNS region, this is not sufficient to affirm that a neurogenic process is taking place, as this process should consist of a series of subsequent steps ultimately producing new neurons that play a role within a specific neural function (Kempermann et al., 2004; Zhao et al., 2006). Thus, we will focus on the assumption that not all neurogenic events can be considered at the same level, taking into account that 'true' adult neurogenesis theoretically extends from the stem/progenitor cell division to the integration of newly generated neurons into functional circuitries. In this review article we highlight that neurogenic processes occurring in the SVZ and SGZ neurogenic sites are more complete and quite constant throughout the species, whereas those described in the parenchyma appear more heterogeneous, possibly reflecting an intrinsic, somehow quiescent, neurogenic potential. Besides some interpretations easily affirming that many regions of the CNS are neurogenic, we consider the global picture in mammals still far from clear, in most cases needing further investigation, while in others simply a deeper comparative discussion. Hence, we try to classify postnatal/adult neurogenic events in mammals starting from a comparative perspective and taking into account the several variables involved, with particular reference to the final outcome of each process in diverse parenchymal regions. In doing so, we also propose a revision/ updating of the relevant terminology in order to couple distinct processes with specific terms.

\section{Differences in SVZ and hippocampal neurogenesis among mammalian species}

Most features of SVZ and hippocampal neurogenesis will not be taken into account in the present review as they have been thoroughly reviewed in previous articles (Kempermann et al., 2004; Lledo et al., 2006; Bonfanti \& Ponti, 2008), and largely shared among mammals. For this reason, here we 
will only focus on species-specific differences.

In the SVZ/olfactory bulb neurogenic system, the main variabilities concern the organization of the SVZ neurogenic niche (Smart et al., 2002; Sanai et al., 2004; Peretto et al., 2005; Ponti et al., 2006a; Quinones-Hinojosa et al., 2006; Sawamoto et al., 2011), with particular reference to its astrocytic pattern and neuroblast migratory cell behaviour (Fig. 1). In rodents, the SVZ is characterized by a dense network of astrocytes forming the so-called glial tubes, which enwrap the chains of migrating neuroblasts engaging in the rostral migratory stream (RMS; Jankovski \& Sotelo, 1996; Lois et al., 1996; Peretto et al., 1997). The density and spatial organization of the SVZ astrocytes vary highly among mammals, forming a thick system of channels in rodents (Jankovski \& Sotelo, 1996; Lois et al., 1996; Peretto et al., 1997) and a looser, incomplete network in other species (Fig. 1). Even among rodents, rats have thicker and more complete glial tubes than mice (Peretto et al., 1997, 2005). An astrocytic meshwork, although not so dense as in rodents, is present in rabbits, associated with very large chains of neuroblasts (Luzzati et al., 2003; Ponti et al., 2006a). The SVZ glial network is far looser in bovines, primates and humans, where it appears reduced to an incomplete 'ribbon' separated from the ependyma by a 'hypocellular gap' (Rodriguez-Perez et al., 2003; Sanai et al., 2004; Quinones-Hinojosa et al., 2006; Gil-Perotin et al., 2009; Sawamoto et al., 2011). Such variability suggests that SVZ astrocytes do not have a primary role as a physical barrier between neuroblasts and mature brain tissue. Instead, they could have an indirect role in cell migration by producing factors; for instance, in mouse RMS a guidance role is attributed to molecular [tenascin C, Ephrins, Slits, brain-derived neurotrophic factor (BDNF), etc.] rather than cellular cues (Conover et al., 2000; Nguyen-BaCharvet et al., 2004; Peretto et al., 2005; Chiaramello et al., 2007).

Besides the possible role of SVZ astrocytes as an anatomical feature of the neurogenic site, they also act as neural stem cells in the form of a radial gliaderived subpopulation hidden among the astrocytic network. Hence, the different cellular organization of glial tubes/meshwork/ribbon observed in different mammals might affect their activity in sustaining neurogenesis. In mice, one possibility is that the active stem cells are those astrocytes that maintain direct contact with the lateral ventricle through a cilium protruding between ependymal cells (Mirzadeh et al., 2008). The occurrence of such contact has also been documented in other mammals (Ponti et al., 2006a; Danilov et al., 2009; Sawamoto et al., 2011).

On the whole, it appears clear that in large-sized brains both astrocytic density and neuroblast assembly in chains are far reduced (Fig. 1B). In general, mammals endowed with larger brains also have a longer lifespan, thus suggesting that SVZ rodent-like features (fast chain migration into a dense astrocytic meshwork) are present when the neurogenic process takes place at high rates. This occurs throughout most of life in short-living organisms (e.g. rodents), whereas it is limited to postnatal/young ages in large-sized, long-living mammals. 


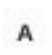

A

Mouse

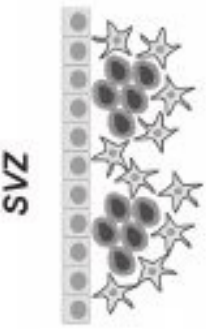

Glial tubes Chains

Doetsoh of ac. (1967)

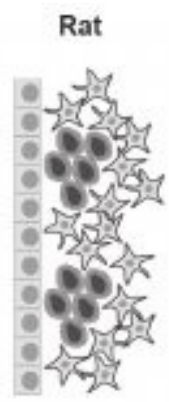

Glial tubes Chains

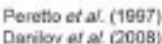

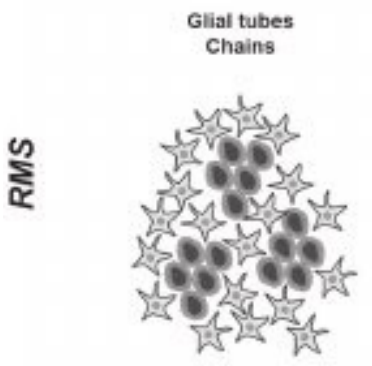

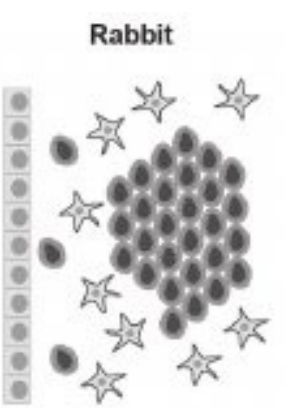

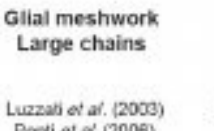

$$
\text { Glial meshwork }
$$$$
\text { Large chains }
$$

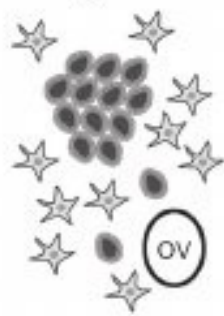

(2003)
Loose glial meshwork lsolated neuroblasts Small chains

Plodiguez-Perez ef at. [2003)

Monkey

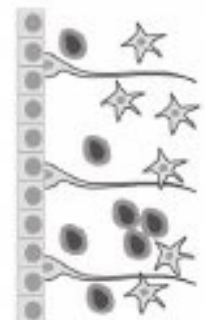

(n)
Axons and astrocytes Chains

Human

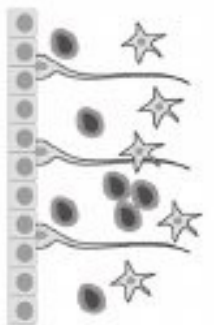

Loose glial meshwork olated neuroblasts Small chains Komack a Rakio, 2001
Perces of at (2001) Gi.Perotinet of $\langle 2006)$

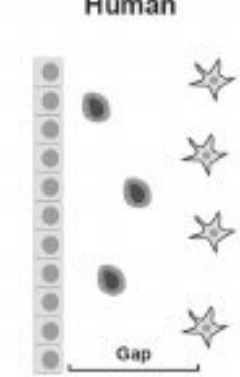

Astrocyte ribbon Isolsted neuroblasts Hipocellutar gap

Sanai ef at. (2004) Dincrsos-Hinojosa of ad, 1200 Oarts of al (2007s)
Curts ef ac (2011)

(occurrence of chains still debated)

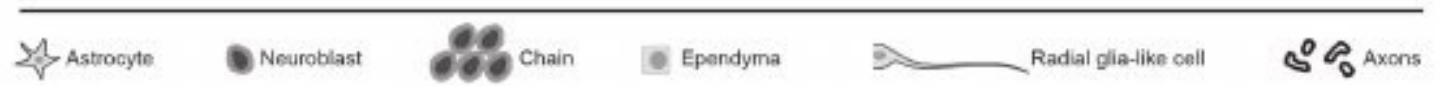

Rodents
(small-sized, short-living)

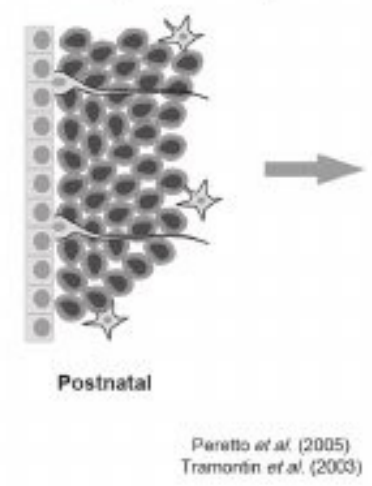

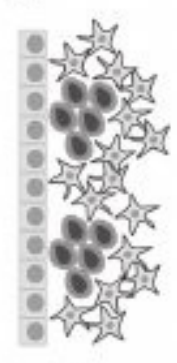

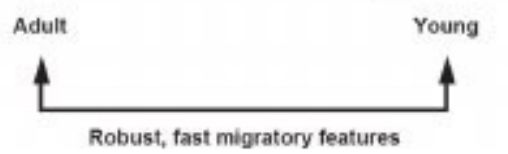

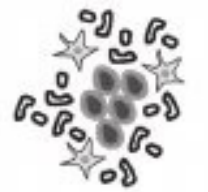

Primates

(large-sized, long-living)

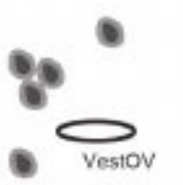

Fig. 1. (A) Organization of the subventricular zone (SVZ) neurogenic niche and rostral migratory stream (RMS) in different mammals. Most differences concern the astrocytic spatial organization and the neuroblast assembly into chains. OV, olfactory ventricle; VestOV, vestigial olfactory ventricle. Type $C$ cells and displaced ependymal cells are not showed. Although still fragmentary, the data available suggest some general principles - (i) chain assembly could be linked to robust and fast cell migration; (ii) chain assembly and cell migration are not directly linked with persistence/closure of the olfactory ventricle; (iii) glial meshwork density is not directly linked with chain assembly; (iv) glial meshwork density is not directly linked with cell migration; (v) astrocytes and axons are not essential for cell migration, yet they constitute a preferable substrate. (B) Short-living mammals with small-sized brains show general features of robust chain migration even during adulthood, whereas long-living mammals endowed with large-sized brains generally retain these features only at postnatal/young ages.

Some discrepancies exist in the overall organization of the RMS, usually considered as a prevalent migratory route rather than a stem cell niche (Gritti et al., 2002). A first difference consists of early postnatal collapse of the 
olfactory ventricle in some mammals (e.g. rodents, monkeys; Smart, 1961; Lois \& Alvarez-Buylla, 1994; Sawamoto et al., 2011), whereas this rostral extension of the lateral ventricle remains open through adulthood in others (e.g. rabbits, bovines, humans; McFarland et al., 1969; Ponti et al., 2006a; Curtis et al., 2007). In rabbits, modifications of the glial network/ventricular system are associated with a remarkable increase in the size of the neuroblast chains, which can even migrate outside the glial barrier in young animals (Luzzati et al., 2003). By contrast, the occurrence of true chains in humans remains controversial (Sanai et al., 2007). On the basis of the current data available, in large-sized brains, for example those of bovines and primates (Rodriguez-Perez et al., 2003; Sanai et al., 2004; Quinones-Hinojosa et al., 2006; Gil-Perotin et al., 2009; Sawamoto et al., 2011), the occurrence of isolated cells (both astrocytes and neuroblasts) is more frequent compared with the occurrence of thick bulks (Fig. 1). The far larger size of most mammalian brains in comparison with the 1.5-cm-long mouse brain undoubtedly constitutes a technical limit in obtaining a complete and detailed description of the complex ventricular system and related SVZ/RMS, especially when time-consuming approaches, such as electron microscopic analyses, are required. Therefore, as far as large brains are concerned, available data are fragmentary due to the variety of approaches used by different authors as well as the different ages / strains investigated. As a result, morphological data concerning this topic in mammals still remain to be clarified.

In the hippocampus, wherein the dentate gyrus loses its contact with the ventricular cavities during development, anatomical heterogeneity is greatly reduced. On the other hand, striking variations do emerge in function rather than structure. For instance, the long-lasting theory that the genesis of new neurons in the dentate gyrus could be generally and constantly involved in spatial memory has been reshaped by the observation that neurogenesis is very low or even absent in bats, namely flying mammals with navigation abilities for 3D-space and thus provided with remarkable spatial working memory (Amrein et al., 2007; Amrein \& Slomianka, 2010). This suggests / confirms the adaptive role of adult neurogenesis and the importance of ecological needs in directing the function of adult neurogenesis, even in neurogenic regions as 'constant' as the hippocampus.

In conclusion, structural differences in cellular organization are more frequent in the SVZ, and could be related to the different anatomical organization of the ventricles (McFarland et al., 1969; Bonfanti \& Ponti, 2008) not affecting the dentate gyrus as a 'parenchymally embedded' structure. Molecular and cellular aspects of persistent neurogenesis seem to be maintained quite constantly throughout the species in both neurogenic systems. The occurrence of similar primary progenitors (radial glia-derived astrocytes) and the subsequent steps of cell specification/differentiation [e.g. the sequential expression of the highly polysialylated form of the neural cell adhesion molecule (PSA-NCAM) and doublecortin (DCX), etc.] follow common patterns in rodents and in other mammals. The difference lies in the anatomical adaptation of these processes to the different brain anatomy and its functional outcome as regards the environment in which the animals live. This could explain the differences in SVZ organization and cell migration between humans and rodents that seem to fit with the fact that the human olfactory bulb makes up approximately $0.064 \%$ of the total brain weight, whereas that of rodents makes up approximately $20 \%$ of the total brain weight (Curtis et al., 


\section{Differences in the so-called non-neurogenic regions}

Despite the variations discussed above, SVZ and hippocampal neurogenesis can be considered as a largely shared feature among mammals. On the other hand, most differences emerging from inter-mammalian comparative studies do involve CNS parenchymal regions outside the neurogenic sites. Starting from a comparative study carried out on primates (Gould et al., 1999), it was firstly hypothesized that some portions of the mammalian CNS parenchyma previously referred to as non-neurogenic could harbour some neurogenic processes. Many subsequent reports confirmed the existence of neurogenic events in other CNS regions (Table 1), most of which were summarized in previous review articles (Emsley et al., 2005; Sohur et al., 2006; Gould, 2007; Bonfanti \& Ponti, 2008; Migaud et al., 2010). Nevertheless, some of the results obtained have not been found in all mammalian species investigated, others have not been reproduced since their first publication or have been denied by other investigators. Such a debate is quite reasonable in a sound scientific community. In some cases, parenchymal neurogenesis is very close to the threshold of detectability ensured by current technical approaches, due to the fact that it occurs at low levels in a few cells that can be dispersed within large portions of CNS tissue. Yet, the question arises - what are the non-neurogenic regions? Are they CNS regions previously considered incapable of neurogenesis in which the genesis of neurons actually occurs (so enriching the list of neurogenic regions) or, rather, do they correspond to regions in which a false-positive result has been obtained (so that the only neurogenic regions remain the SVZ and SGZ)? In between these two extremes we propose a third explanation, in which some of the previously called nonneurogenic regions are endowed with low-level, 'incomplete' neurogenic processes (see below). Thus, to correctly analyse this issue it is impossible to make a simple list of the topographical sites harbouring neurogenesis in mammals, a distinction is to be made between different aspects of the neurogenic process. First of all, the temporal extension of neurogenesis during postnatal/adult periods is highly variable in different species and CNS regions. This aspect will be analysed in the following paragraph in order to isolate true adult neurogenic processes from early postnatal extensions of embryonic neurogenesis. Then, in the subsequent sections of the review, by focusing on adult neurogenesis in the parenchyma we will address the variables at the basis of its heterogeneity, such as the final outcomes produced at different steps of the neurogenic process (complete and incomplete neurogenesis), and its nature as either a spontaneous event in the intact CNS (constitutive, physiological neurogenesis) or induced after experimental/ pathological conditions (potential, lesion-induced neurogenesis). 
Table 1. Neurogenesis in 'non neurogenic regions' of the adult mammalian brain

\begin{tabular}{|c|c|c|c|c|c|c|c|}
\hline & Rats & & Mice & & Rabbits & Monkeys & \\
\hline \multirow[t]{2}{*}{ Neocortex } & $\begin{array}{l}\text { Gould et al., } 2001 \\
\text { Dayer et al., 2005 } \\
\text { Tamura et al., } 2007\end{array}$ & $\begin{array}{l}1-3 \\
1-4 \\
1,2,(3)\end{array}$ & Shapiro et al., 2009; & $1,(2,3)$ & n.e. & $\begin{array}{l}\text { Gould et al., 1999, } 2001 \\
\text { Bermier et al., 2002; }\end{array}$ & $\begin{array}{l}1-3 \\
1-3\end{array}$ \\
\hline & $\begin{array}{l}\text { Nakatomi et al., } 2002 \\
\text { Pencea et al., } 2001 \\
\text { Ohira et al. } 2010\end{array}$ & $\begin{array}{l}1-3 \\
1,(2,3) \\
1-4,(5)\end{array}$ & $\begin{array}{l}\text { Magavi et al., 2000; } \\
\text { Chen et al., 2004; }\end{array}$ & $\begin{array}{l}1-4,(5) \\
1-4,(5)\end{array}$ & n.e. & Vessal \& Darian-Smith, 2010; & $1-4$ \\
\hline \multirow[t]{2}{*}{ Corpus callosum } & n.e. & & n.e. & & n.e. & & n.e. \\
\hline & Pencea et al., 2001 & $1,(2,3)$ & n.e. & & n.e. & & ne. \\
\hline Piriform cortex & $\begin{array}{l}\text { Pekcec et al., } 2006 \\
\text { n.c. }\end{array}$ & $1,(2,3)$ & $\begin{array}{l}\text { Shapiro et al., 2007; } \\
\text { n.e. }\end{array}$ & $1,(2,3)$ & $\begin{array}{l}\text { n.e. } \\
\text { n.e. }\end{array}$ & Bernier et al., 2002; & $\begin{array}{l}1-3 \\
\text { ne. }\end{array}$ \\
\hline Olfactory tubercle & $\begin{array}{l}\text { n.e. } \\
\text { n.e. }\end{array}$ & & $\begin{array}{l}\text { Shapiro et al., } 2009 \\
\text { n.e. }\end{array}$ & $1,(2,3)$ & $\begin{array}{l}\text { n.e. } \\
\text { n.e. }\end{array}$ & Bédard et al., 2002b; & $\begin{array}{l}1,2(3) \\
\text { n.e. }\end{array}$ \\
\hline \multirow[t]{2}{*}{ Striatum } & $\begin{array}{l}\text { Dayer et al., } 2005 \\
\text { Arvidsson et al. } 2002\end{array}$ & $1-4$ & $\begin{array}{l}\text { Shapiro et al., 2009; } \\
\text { Yamashita et al. 2006: }\end{array}$ & $\begin{array}{l}1,(2,3) \\
1-3,(4,5)\end{array}$ & Luzzati et al., 2006; 1-4 & Bédard et al., 2002a, 2006 & $1-3$ \\
\hline & $\begin{array}{l}\text { Pencea et al., } 2001 \\
\text { Liu et al., } 2009\end{array}$ & $\begin{array}{l}1,(2,3) \\
1-4\end{array}$ & Cho et al., 2007; & $1-4$ & n.e. & & n.e. \\
\hline \multirow[t]{2}{*}{ Septum } & n.e. & & n.e. & & n.e. & & n.e. \\
\hline & Pencea et al., 2001 & $1,(2,3)$ & ne. & & n.e. & & n.e. \\
\hline \multirow{2}{*}{ Amygdala } & n.e. & & Shapiro et al., 2009 & $1,(2,3)$ & Luzzati et al., 2006; 1-3 & Bernier et al., 2002; & $1-3$ \\
\hline & n.e. & & ne. & & n.e. & & n.e. \\
\hline $\begin{array}{l}\text { Hippocampus } \\
\text { (hammon's horn) }\end{array}$ & $\begin{array}{l}\text { n.e. } \\
\text { Nakatomi et al., } 2002\end{array}$ & $1-5$ & $\begin{array}{l}\text { Rietze et al., } 2000 \\
\text { n.e. }\end{array}$ & $1,(2,3)$ & $\begin{array}{l}\text { n.e } \\
\text { n.e. }\end{array}$ & & $\begin{array}{l}\text { n.e. } \\
\text { n.e. }\end{array}$ \\
\hline \multirow[t]{2}{*}{ Thalamus } & n.e. & & ne. & & n.e. & & n.e. \\
\hline & Pencea et al., 2001 & $1,(2,3)$ & n.e. & & n.e. & & n.e. \\
\hline \multirow[t]{4}{*}{ Hypothalamus } & Xu et al, 2005 & $1,(2,3)$ & Kokoeva et al., 2007; & $1,(2,3)$ & n.e. & & n.e. \\
\hline & Xu et al., 2005 & $1-3,(4)$ & $\begin{array}{l}\text { Kokoeva et al., 2005; } \\
\text { Pierce \& } X_{u} \text { 2010 }\end{array}$ & $1-3,(4)$ & & & \\
\hline & $\begin{array}{l}\text { Pencea et al., 2001 } \\
\text { Matsuzaki et al., } 2009\end{array}$ & $\begin{array}{l}1,(2,3) \\
1,(2-4)\end{array}$ & Pierce \& Xu, 2010; & $1,(2-4)$ & n.e. & & n.e. \\
\hline & Pérez-Martin et al., 2010 & $1,(2,3)$ & & & & & \\
\hline \multirow[t]{2}{*}{ Substantia nigra } & n.e & & $\begin{array}{l}\text { Zhao et al., } 2003 \\
\text { Zhao \& Janson } \\
\text { Lang, 2009 }\end{array}$ & $\begin{array}{l}1,(2-4) \\
(4)\end{array}$ & n.e & & n.e. \\
\hline & n.e. & & Zhao et al., 2003 & $1,(2-4)$ & n.e. & & ne. \\
\hline \multirow[t]{2}{*}{ Cerebellum } & n.e & & n.e & & $\begin{array}{l}\text { Ponti et al., } \\
2008\end{array}$ & n.e. & \\
\hline & n.e. & & n.e. & & n.e. & & n.e. \\
\hline \multirow[t]{2}{*}{ Brainstem } & Bauer et al., 2005 & $1,(2,3)$ & n.e. & & n.e. & & ne. \\
\hline & Bauer et al., 2005 & $1,(2,3)$ & n.e. & & n.e. & & ne. \\
\hline
\end{tabular}

White lines, spontaneous (constitutive) neurogenesis; shaded lines, induced neurogenesis (growth factor infusion, lesion). Only a set of studies are reported. Numbers 1 to 5 are referred to the levels of neurogenesis reported in Figs. 4, 7, and in Table 2 - 1, cell proliferation; 2, cell genesis; 3 , cell specification; 4, neurogenesis; 5 , functional integration. In parenthesis, less accurate analyses (reslicing not performed, neurogenesis not clearly shown, very few cells showed in figures, insufficient or absent quantification, etc.); n.e., not yet evaluated/published.

\section{Temporal extension of constitutive neurogenesis - postnatal neurogenesis in young mammals}

The end of developmental neurogenesis is highly heterogeneous in the mammalian species. Most of the neurons are generated postnatally, following a wide range of temporal windows. The majority of these neurons are granule cells, namely small-sized, relatively uniform neurons morphologically, yet displaying remarkable differences in their function and neurotransmitter content (Kuhn \& Blomgren, 2011). This general behaviour of delayed neurogenesis shows differences among mammalian species, concerning both topographical and temporal variations within the same brain region. Because we know that neurogenic processes continue throughout life in regions such as the olfactory bulb and the dentate gyrus, a distinction should be made between 'protracted' neurogenesis, as a transitory extension of the developmental neurogenesis for some periods after birth, and 'persistent' 
neurogenesis, namely a constitutive neurogenic process that can decrease in intensity but does not come to an end (Fig. 2). More precisely, protracted neurogenesis should be viewed as a morphogenetic process accomplished after birth (Fig. 2, black fields). The mouse olfactory bulb is a typical example - postnatal morphogenesis involving glomerular formation is delayed until the first week after birth (Bailey et al., 1999), then, persistent neurogenesis from the SVZ grants interneuron turnover throughout life.

In mammals, the most striking prototype of protracted neurogenesis is the cerebellum. Although the genesis of most cerebellar cell types occurs very early from the periventricular neuroepithelium lining the 4 th ventricle, interneurons and some astrocytic glial cells complete their centrifugal migration through the white matter and their specification postnatally (Maricich \& Herrup, 1999; Grimaldi et al., 2009). Cell proliferation of these

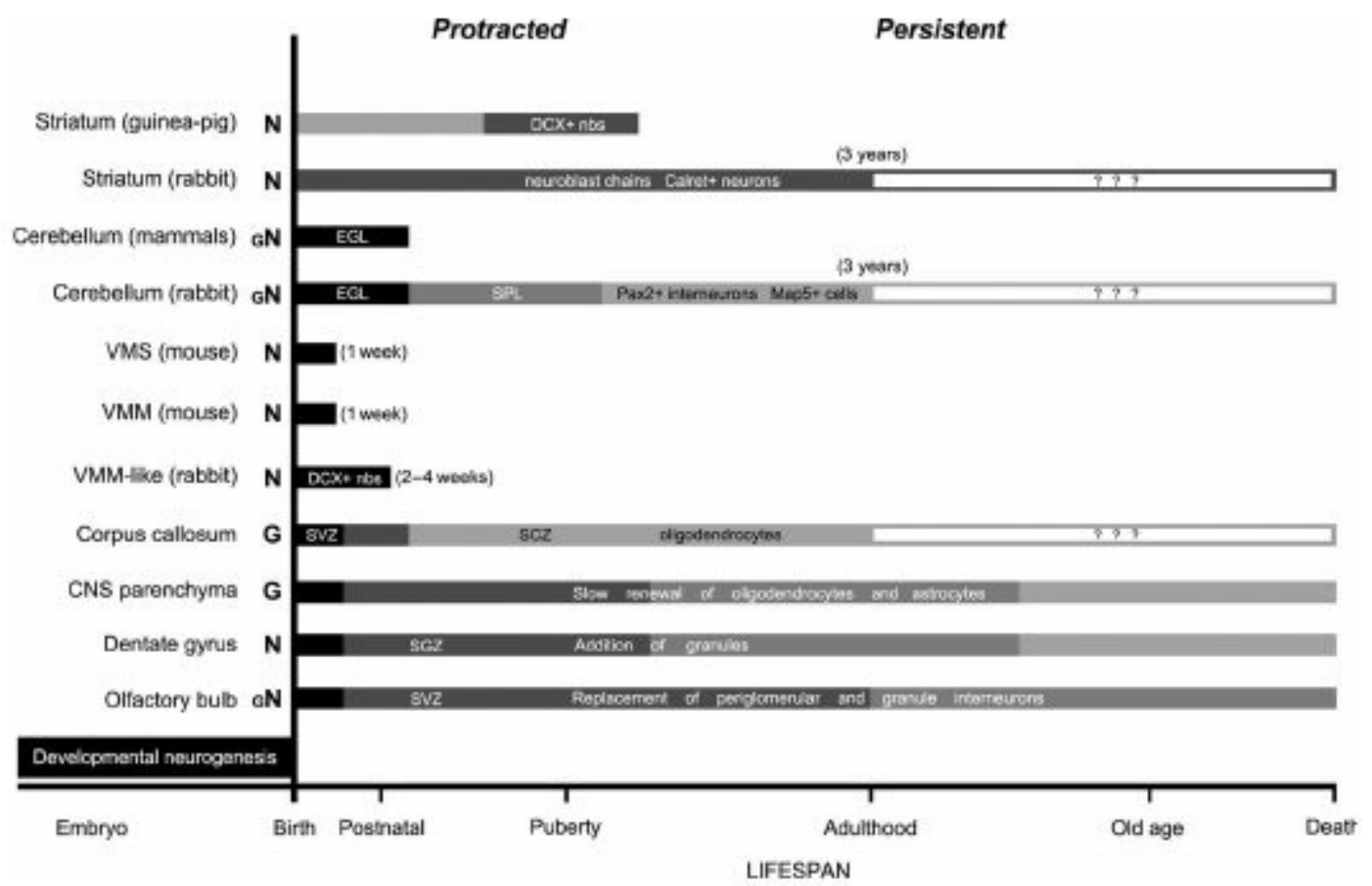

Fig. 2. Different developmental extensions of protracted and persistent neurogenesis. Black, postnatal extensions of embryonic neurogenesis (delayed morphogenesis). Shades of grey indicate different rates of cell genesis, usually decreasing with increasing age (note the exception of the guinea pig). DCX, doublecortin; EGL, external granule layer; G, glial progeny; gN, glial and neuronal progeny (prevalently neuronal); Map5, microtubule-associated protein 1B; N, neuronal progeny; nbs, Neuroblasts; SCZ, subcallosal zone; SGZ, subgranular zone; SPL, subpial layer; SVZ, subventricular zone; VMM, ventral migratory mass; VMS, ventral migratory stream.

progenitors still occurs in prospective white matter. In addition, the postnatal mammalian cerebellum undergoes a protracted genesis of granule cells through a transitory, secondary germinative layer localized on its surface, that is, the external germinal layer (EGL). The EGL is formed by tangential subpial displacement of cell precursors from the germinal trigone of the 4 th ventricle, then leads to protracted genesis of the granule cell population by radial, centripetal migration of cell precursors. This transitory germinal zone progressively reduces its thickness as the granule cell precursors migrate deep into the cortex, then disappear at specific ages in different species (from 3 weeks in mice to 11 months in humans, which is very early compared with puberty; reviewed in Ponti et al., 2008, 2010). In rodents, the delayed 
proliferation, specification and differentiation of glial cells and interneurons coming from the prospective white matter is concluded before the end of granule cell genesis (Grimaldi et al., 2009; Leto et al., 2009). After this stage, no more cell genesis is detectable, as no germinal layers remain active, so that cerebellar plasticity throughout life is granted solely by synaptic changes in pre-existing circuits. Under the functional profile, this delayed genesis of granule cells and interneurons shares a logic with the role of cerebellar circuits in learning / adapting motor skills to the environmental cues the animal is dealing with during postnatal/young stages of its life. This process does not involve simply the addition of new neurons, but also the choice between different types of cell specification (Grimaldi et al., 2009; Leto et al., 2009). The delayed cerebellar neurogenesis might be considered as part of the critical periods that allow formation of new synaptic contacts as well as involving the recruitment of new neurons. Recent comparative work carried out on the cerebellum of New Zealand white rabbits revealed a far more complex situation, as in these lagomorphs protracted neurogenesis extends around and beyond puberty (Ponti et al., 2006b). Subsequently, it persists during adulthood to a lesser extent (Ponti et al., 2008; Figs 2 and 3). Unlike most mammals, cell proliferation on the rabbit cerebellar surface extends beyond puberty, up to the fifth month of age. Starting from the second month of life, the germinal layer hosting such proliferation (subpial layer, SPL) acquires features that are different from the EGL, consisting of tangential chains of neuroblasts that share the same cytology and cellular markers of SVZ chains of neuroblasts (Ponti et al., 2006b, 2010). The rabbit SPL spans from 1 to 5 months of age, persisting shortly beyond puberty, yet it is not just an 'extension in time' of the EGL as the descent of granule cell precursors is exhausted long before puberty. The role of rabbit SPL persistence remains unresolved, although it could be involved in the tangential displacement of neuronal precursors, as described in the mouse EGL pre-migratory layer prior to engagement in radial migration (Komuro et al., 2001). Even after SPL disappearance, local neurogenesis persists in the rabbit cerebellar cortex (see below for more detail). The intensity of such a process, which has been documented in adult rabbits up to 3 years old, progressively decreases (10/1 in the first 6 months, and once again 10/1 from 6 months to 3 years; Ponti et al., 2008). Subsequent ages have not been investigated, yet the substantial decrease in newly generated cerebellar neurons suggests a further dilution/ exhaustion of the process in older rabbits, thus representing a case of protracted rather than persistent neurogenesis. These results obtained in the rabbit show that remarkable differences may exist in mammals, perhaps requiring further comparative re-examination of postnatal cerebellar development by taking into account different functional aspects. Little is known about what factors determine the timing of the onset of walking, which represents a fundamental milestone in motor development of mammals (altricial vs. precocial mammals; Sanchez-Villagra \& Sultan, 2001). Hoofed animals start walking within hours after birth, both rodents and small carnivores require days or weeks, and non-human primates take months (humans approximately 1 year) to achieve this locomotor skill (Garwicz et al., 2009). 

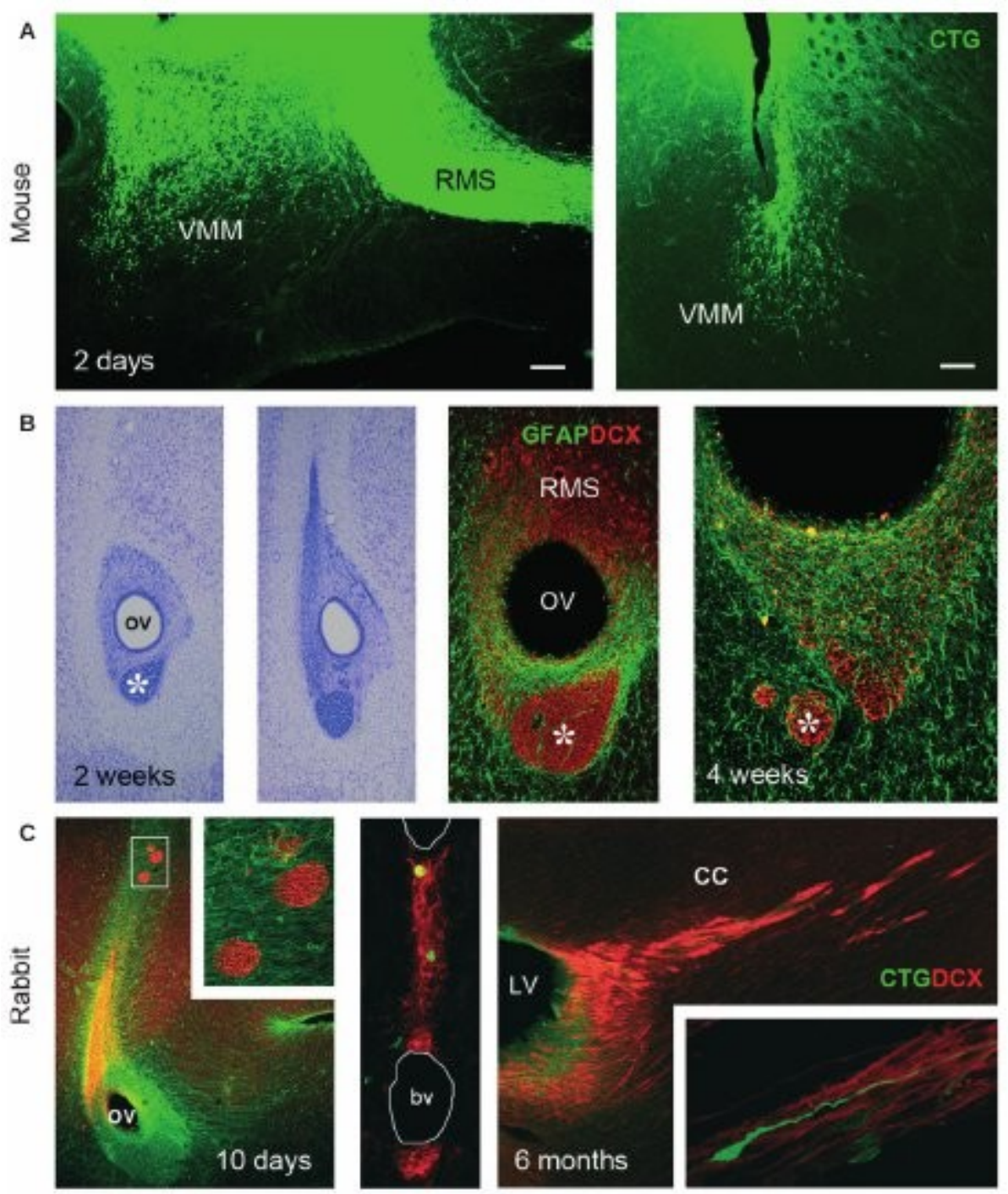

D
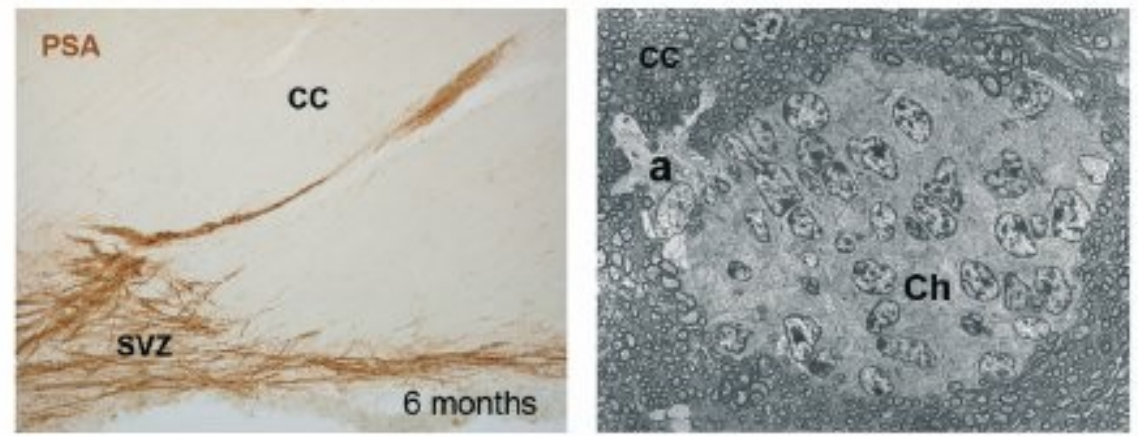

Fig. 3. Some examples of protracted neurogenesis in different mammalian species. (A and B) Early postnatal displacement of neuroblasts through migration routes connected with the rostral migratory stream (RMS). CTG, cell tracer green; DCX, doublecortin; GFAP, glial fibrillary acidic protein; VMM, ventral migratory mass in mice and a similar pathway in rabbits (asterisk in B). (C and D) Parenchymal chains (Ch) of neuroblasts leaving the subventricular zone (SVZ) of young rabbits and directed towards the corpus callosum (CC). a, astrocyte; bv, blood vessel; LV, lateral ventricle; OV, olfactory ventricle; PSA, highly polysialylated form of the neural cell adhesion molecule. (A) Courtesy of S. De Marchis; (B-D) from Ponti et al. (2006a) and Luzzati et al. (2006). 
Another case of protracted neurogenesis is that of secondary migratory pathways (Fig. 2). In the mouse subcortical forebrain, in addition to the RMS, some SVZ-derived progenitors migrate in a ventral migratory mass (VMM) across the nucleus accumbens into the basal forebrain, giving rise to granule neurons in the islands of Calleja (De Marchis et al., 2004; Fig. 3A). Another group of cells migrate along a ventrocaudal migratory stream (VMS) originating at the elbow between the vertical and horizontal limbs of the RMS, then reaching the olfactory tubercle pyramidal layer (De Marchis et al., 2004). In the rabbit, large masses of DCX+ neuroblasts similar to the mouse VMM are present in the ventral part of the olfactory ventricle (and RMS; Fig. 3B) during the first postnatal month (Ponti et al., 2006a). In young rabbits, up to puberty, SVZ-derived parenchymal chains can still leave the neurogenic zone migrating outside the astrocytic glial meshwork to reach the frontal cortex (Luzzati et al., 2003; Ponti et al., 2006a; Fig. 3C and D). These cells, whose ultimate function and possibility for survival remain obscure, are generated within the SVZ and then migrate through the corpus callosum as postmitotic neuroblasts (Ponti et al., 2006a). Finally, worthy of mention is the case of nonplacental mammals that are born in an immature state, for example the opossum (Monodelphis domestica, belonging to Metatherians or marsupials). The CNS of these animals at birth corresponds to 14-day mouse embryos, which allows the spinal cord to regenerate after a lesion up to P9-12 (Mladinic et al., 2009). Unfortunately, despite substantial knowledge about CNS regenerative capacity in opossum, very little is known about constitutive neurogenesis in these animals.

Hence, the extension of postnatal neurogenesis in young mammals is highly variable as to the species and the CNS regions considered, the former being strictly related to puberty and lifespan, the latter to the animal lifestyle. Regarding the source of the newly generated cells, in some cases the protracted neurogenesis is linked to the transient persistence of germinal layers (e.g. EGL, SPL), yet it can also be sustained by local progenitors (e.g. rabbit cerebellum; Fig. 5). Nevertheless, it is worthwhile pointing out that the difference between protracted and persistent neurogenesis could not have any sharp boundaries. The point at which sexual maturity occurs during the lifespan in mammals is highly variable, so that remarkable variations also exist in defining 'adulthood' in different species (Lindsey \& Tropepe, 2006). In addition, important species-specific variations can involve the time course of developmental neurogenesis, such as in primates, which have evolved an expanded isocortex by selectively delaying neurogenesis, expanding the SVZ and delaying maturation (Smart et al., 2002; Charvet \& Striedter, 2011). Finally, the time course of persistent neurogenesis in elderly individuals is also subject to changes. The issue concerning how fast its rate decreases with age has been answered in rodents (Kempermann et al., 2003; Luo et al., 2006); however, it remains quite undetermined in other mammalian species. 

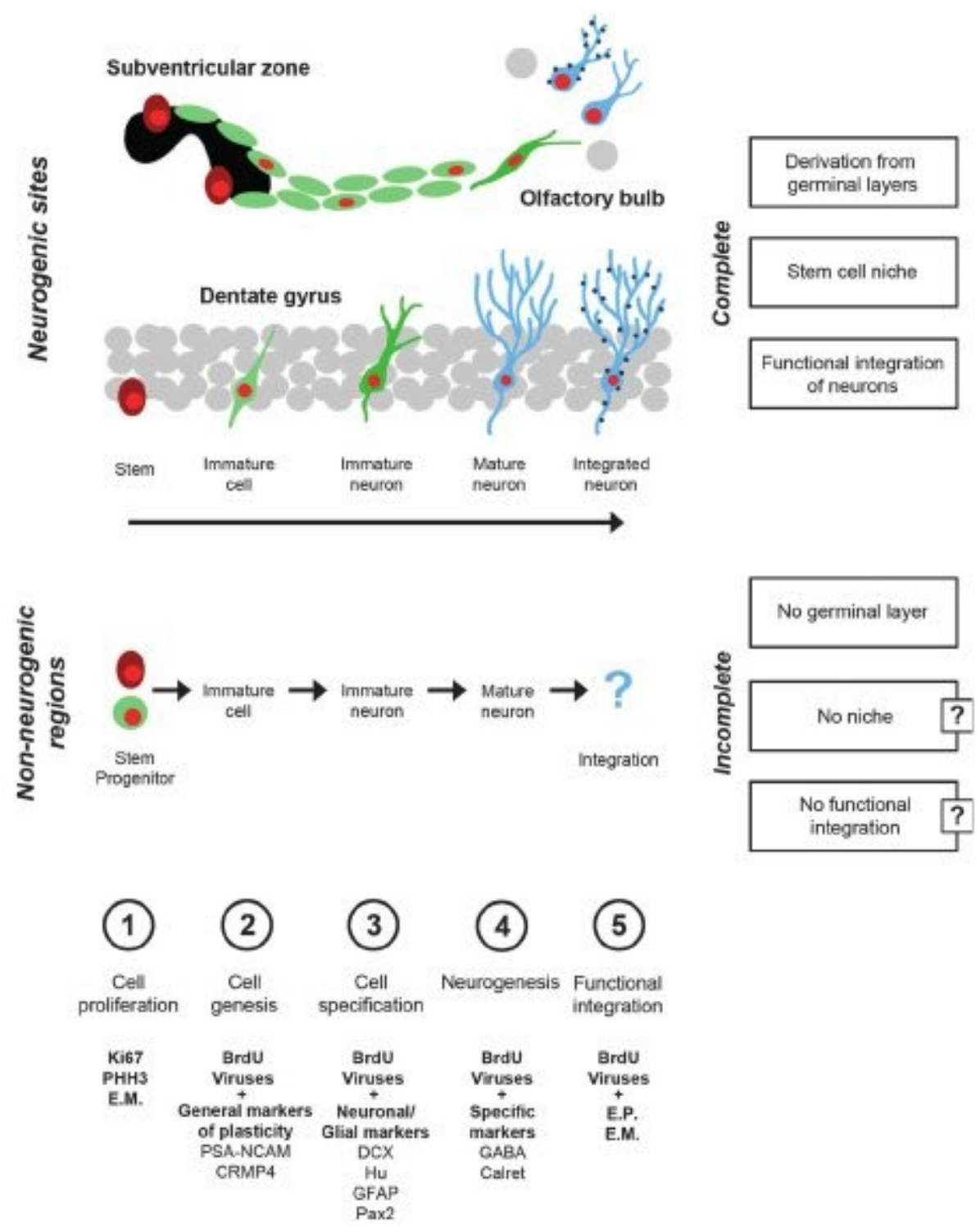

Fig. 4. Different aspects of neurogenic processes in mammalian neurogenic sites (top) and non-neurogenic regions (middle); common steps in the genesis of new neurons (bottom; Table 2). Red nuclei, markers of proliferation/lineage that can be associated with specific cell markers (bottom). The two brain neurogenic sites are germinal layer-derived and host wellcharacterized stem cells and niches; within these sites the whole process from the stem cell division to the mature neuron functional integration has been demonstrated to occur (complete neurogenesis). By contrast, the CNS parenchymal regions (so-called nonneurogenic) are not directly related with germinal layers and lack well-defined neurogenic niches; the sources of parenchymal neurogenesis are still unclear as to their nature of stem / progenitor cell properties and remarkably vary in different brain regions. In non-neurogenic regions, most of the evidences for neurogenesis are interrupted at various intermediate levels (incomplete neurogenesis). BrdU, 5-bromo-2\$-deoxyuridine; DCX, doublecortin; E.M., electron microscopy; E.P., electrophysiology; GABA, c-aminobutyric acid; GFAP, glial fibrillary acidic protein; PHH3, mitotic phosphorylated amino-terminal form of the histone H3; PSA-NCAM; highly polysialylated form of the neural cell adhesion molecule. 
Developmental time course: postnatal/adult neurogenesis

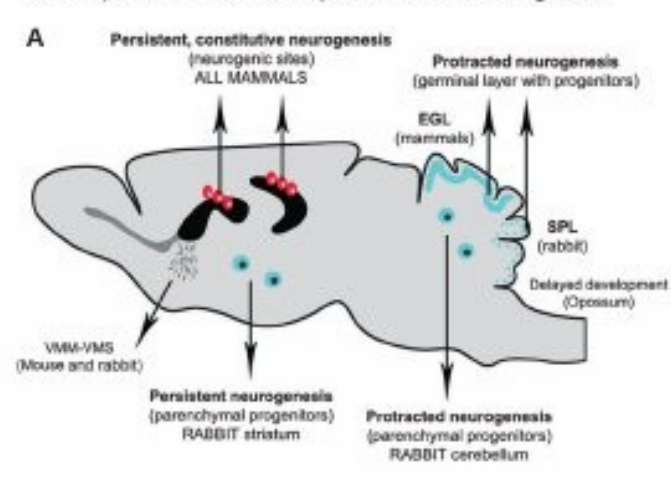

Gliogenesis and its variants
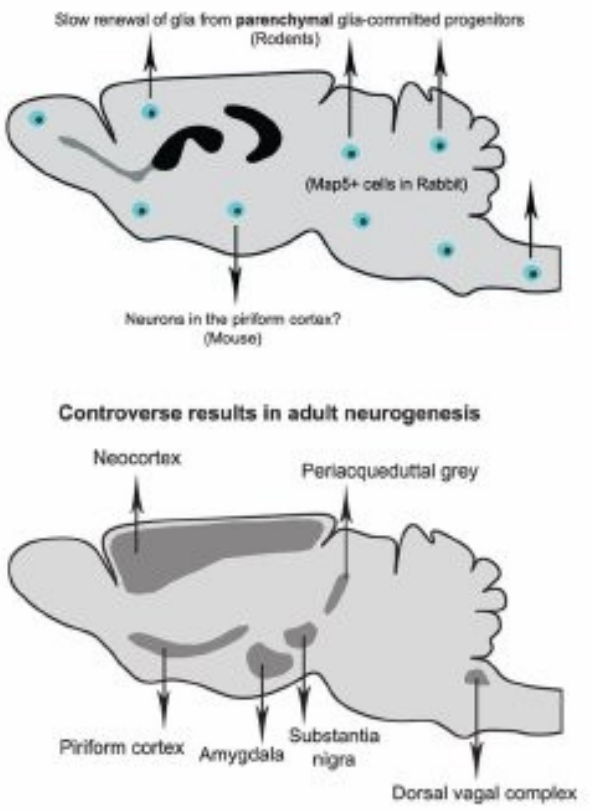

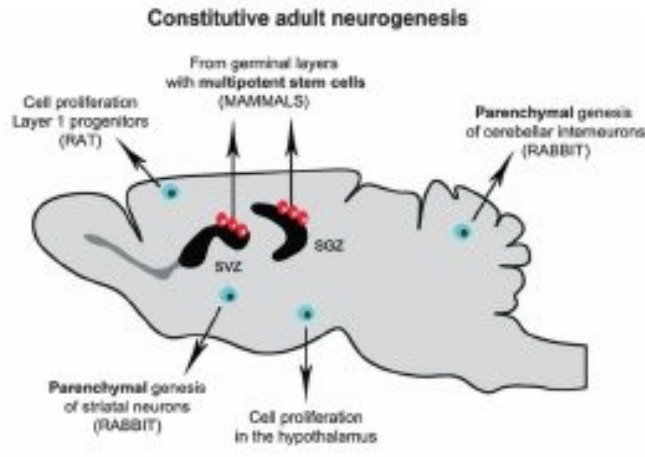

Induced (reactive) adult neurogenesis

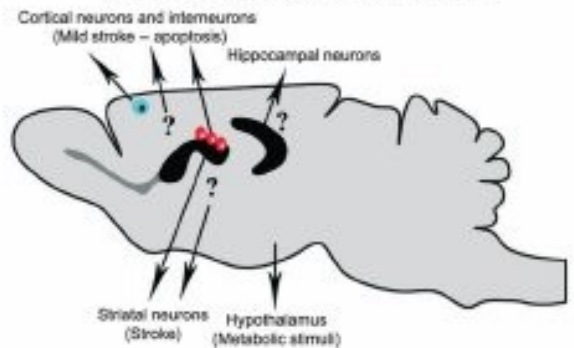

Comparative adult mammalian neurogenesis

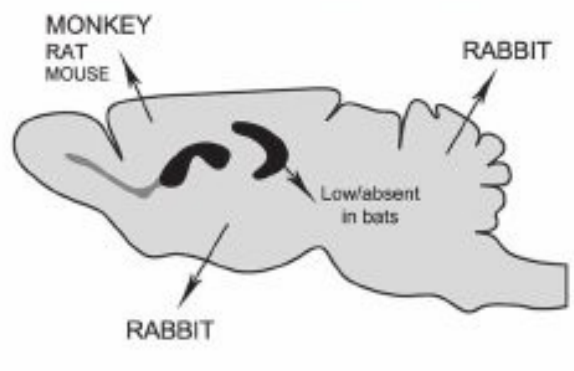

B
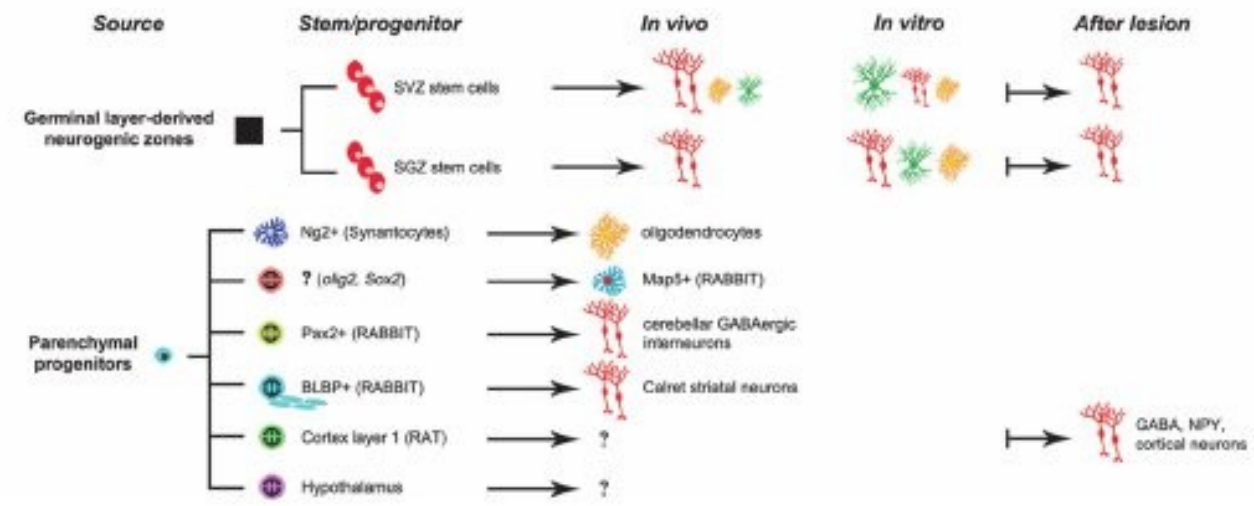

Fig. 5. Heterogeneity of postnatal/adult neurogenic processes in different mammals by considering different aspects (A), including the postnatal developmental stage, the spontaneous neurogenesis and gliogenesis in different CNS regions, the induction of neurogenesis after various experimental/pathological conditions, some controversial localizations. In the bottom right figure, the main differences emerging from comparative neurogenesis in mammals are summarized. (B) Schematic summary of the main sources (progenitor cells) of adult mammalian neurogenesis, its outcome in vivo/in culture system, and its possible activation after lesion. In the case of many non-neurogenic regions, some of these steps are still obscure. BLBP, brain lipid-binding protein; EGL, external germinal layer; GABA, c-aminobutyric acid; Map5, microtubule-associated protein 1B; Ng2, nerve/glial antigen 2 proteoglycan; NPY, Neuropeptide Y; SGZ, subgranular zone; SPL, subpial layer; SVZ, subventricular zone; VMM, ventral migratory mass; VMS, ventrocaudal migratory stream. 
In the context of protracted neurogenesis, it is worth mentioning that gliogenesis is generally delayed compared with neurogenesis. In this case, due to a slow, widespread proliferative activity of some glial progenitors that persists in the adult CNS parenchyma (see below; paragraph on gliogenesis), an overlap with the postnatal wave of gliogenesis does exist. Nevertheless, postnatal gliogenesis is a massive process primarily providing axonal myelinization, as consistently shown in the rat corpus callosum during the first 2-4 weeks of life (Levison \& Goldman, 1993), whereas some functional aspects of constitutive adult gliogenesis still remain obscure. The genesis and migration of oligodendrocyte precursors from the adult SVZ to the corpus callosum remain active throughout life both in physiological and pathological states (Picard-Riera et al., 2002; Nait-Oumesmar et al., 2007). In particular, a specific subregion of the SVZ located at the limit between hippocampus and corpus callosum, and known as the subcallosal zone, is particularly active as a source of oligodendrocyte precursors (Seri et al., 2006).

In conclusion, all examples of protracted neurogenesis occur for transitory, postnatal periods as an extension of embryonic neurogenesis aimed at building specific brain regions (with differences potentially related to speciesspecific adaptations), then being exhausted at different stages. For this reason, protracted neurogenesis, as an aspect of development, and persistent (adult) neurogenesis, as a form of life-long neural plasticity, should be kept separate.

\section{Heterogeneity of adult parenchymal neurogenesis in mammals}

As suggested above, adult neurogenesis in the so-called nonneurogenic regions (parenchymal neurogenesis) shows substantially different features from the one known in the neurogenic sites (SVZ and SGZ), as it is more heterogeneous. The existence or absence of the neurogenic process (regionalization) is linked to species-specific differences, which confirms the need for comparative analyses to reach an in-depth picture in mammals. In addition, another kind of heterogeneity concerns qualitative/ quantitative characteristics of the process itself, such as - (i) its dual nature of spontaneous event in the intact CNS (constitutive, physiological neurogenesis) and / or inducible process after experimental/pathological conditions (potential, lesion-induced neurogenesis); and (ii) the level reached by the neurogenic process as to its final outcome, here referred to as 'complete' and 'incomplete' neurogenesis. The existence of these multifaceted aspects implies the proper use of related terminology by adapting the current definitions to this new heterogeneity.

Constitutive neurogenesis is the spontaneous, continuous genesis of new neurons as part of a physiological, homeostatic process (Emsley et al., 2005). It primarily occurs in the SVZ and SGZ neurogenic sites, wherein neurons and, to a lesser extent, glial cells are continuously generated throughout life (Kempermann et al., 2004; Lledo et al., 2006). In these neurogenic zones, the long-lasting persistence of the process itself is granted by the presence of bona fide stem cells, which persist from primitive embryonic germinal layers and are harboured within a specific microenvironment capable of regulating their activity - the stem cell niche (Doetsch, 2003; Kriegstein \& AlvarezBuylla, 2009; Fig. 4). 
In addition, several examples of constitutive neurogenesis have been reported outside the two classic neurogenic sites (Table 1, white lines). They have been described in rodents (Dayer et al., 2005; Kokoeva et al., 2005), rabbits (Luzzati et al., 2006; Ponti et al., 2008) and monkeys (Gould et al., 1999; Bernier et al., 2002). This suggests that constitutive neurogenesis might exist in the mammalian CNS parenchyma, even in the absence of evidence for germinal layer-derived stem cell niches, which may depend on the species (Ponti et al., 2010).

Beside spontaneous neurogenesis, it is becoming increasingly clear that basal levels of neurogenic activity can increase dramatically under specific physiological, experimental and pathological stimulation (see for example, Arvidsson et al., 2002; Emsley et al., 2005; Ohira et al., 2010; Table 1, grey lines). What remains irresolute is whether spontaneous and lesion-induced neurogenesis follow the same pathways and/or involve the same progenitors. In fact, stem/progenitor cells of the parenchymal regions compared with those in neurogenic sites are far more heterogeneous as regards their nature and potentialities (for more detail see below, paragraph on gliogenesis). Constitutive neurogenesis occurring in germinal layer-derived neurogenic sites can be considered complete, as it leads to functional integration of newlyborn neurons playing a role in homeostasis (by replacing dead neurons or adding to preexisting populations; Kempermann et al., 2004; Lledo et al., 2006; Imayoshi et al., 2008). On the other hand, what was revealed in nonneurogenic regions both in physiological and lesion-induced conditions mostly appears incomplete (Fig. 4). Theoretically, this aspect could be linked to technical limits in the detection of very low levels of parenchymal neurogenesis, both considering the identification of cell proliferation and that of cell lineage. The issue of cell proliferation has common bases and was widely analysed in previous articles (Nowakowski \& Hayes, 2000; CooperKuhn \& Kuhn, 2002; Gould \& Gross, 2002; Rakic, 2002; Breunig et al., 2007; Bonfanti \& Ponti, 2008), whereas the task of following the fate of the newlyborn elements through time (including the specification, differentiation, possible migration and final integration) appears more heterogeneous and requires more complex approaches. Nevertheless, a vast number of reports currently published in the domain of parenchymal neurogenesis, although accurate and carried out with multiple technical approaches, do suggest that in most cases newly formed elements barely survive and do not fully integrate. In order to critically evaluate / compare neurogenic events among diverse mammalian species/regions, in the present review we have dissected five subsequent levels in the neurogenic processes that could be reliable and 'transversal' for diverse cell types and neurogenic systems, spanning from cell division to possible integration of specified/differentiated elements into the CNS tissue (Table 2). When any of these five steps are unfulfilled, the neurogenic process should be classified as incomplete.

In the next paragraph (and related Table 1) parenchymal neurogenesis in mammals will be reviewed by taking into account not only its occurrence / absence in different species / regions, but also the two main aspects of heterogeneity - constitutive vs. lesion-induced neurogenesis (indicated with white and grey lines in Table 1); and complete vs. incomplete neurogenesis (steps 1-5 in Tables 1 and 2; Fig. 4). 
Table 2. Subsequent basic biological steps from genesis to integration, theoretically occurring in any newly generated cell, independently from specific regional/species features

\begin{tabular}{|c|c|c|}
\hline Level of neurogenesis (biological steps) & Tools and approaches for detection & Outcome \\
\hline Level 1 (cell division) & $\begin{array}{l}\text { Detection of specific endogenous/exogenous markers of cell proliferation } \\
\text { (e.g., Ki67, PHH3, BrdU) }\end{array}$ & Cell proliferation \\
\hline Level 2 (cell genesis) & $\begin{array}{l}\text { Association of level } 1 \text { (BrdU/viral cell tracing) with cytoplasmic, } \\
\text { cytoskeletal, or membrane-bound molecules (general markers of plasticity } \\
\text { expressed in highly undifferentiated cells, such as stem/progenitor cells } \\
\text { and their early progeny; e.g., BLBP, Mash1, Sox2, PSA-NCAM, CRMP4, } \\
\text { Map5) }\end{array}$ & $\begin{array}{l}\text { Cell survival and general } \\
\text { features (shape, position) }\end{array}$ \\
\hline Level 3 (cell specification) & $\begin{array}{l}\text { Association of level } 1 \text { (BrdU/viral cell tracing) with markers or } \\
\text { transcription factors for specific neuronal and glial lineages (e.g., DCX, } \\
\text { Hu, NeuN, Olig2, Sox 10) }\end{array}$ & $\begin{array}{l}\text { Cell survival and lineage } \\
\text { (neuronal, glial) }\end{array}$ \\
\hline Level 4 (neurogenesis) & $\begin{array}{l}\text { Association of level } 1 \text { (BrdU/viral cell tracing) with reliable markers for } \\
\text { identifying specific neuronal or glial populations - neurotransmitters, } \\
\text { molecules associated with cell populations in specific brain regions, etc. } \\
\text { (e.g., GABA, calretinin) }\end{array}$ & $\begin{array}{l}\text { Cell survival and specific } \\
\text { neuronal/glial cell type }\end{array}$ \\
\hline Level 5 (functional integration) & $\begin{array}{l}\text { Association of level } 1 \text { (BrdU/viral cell tracing) with electron } \\
\text { microscopic/electrophysiological/behavioural approaches showing the } \\
\text { integration into preexisting neural circuits. }\end{array}$ & Cell survival and function \\
\hline
\end{tabular}

Different steps of cell genesis and differentiation have been described in various developmental and adult neurogenic systems (Guillemot, 2007; Kempermann et al., 2004; Zhao et al., 2006). Here, the basic biological steps shared by newly generated cells, independently from regional/system differences, are represented. Endogenous cell divison markers (Ki67, PHH3) detect phases of the cell cycle, yet not allow the visualization of other cell features and morphological aspects (shape, migration, emission of neurites, etc.). Thus, level 1 must be followed by the whole visualization of cell morphology and proof of its longterm survival by using exogenous markers / viruses associated with specific cell markers. The simultaneous localization of multiple markers can add further information about the identity of the newly generated cells. Some of these markers can be overlapping in different differentiative stages, temporal windows, and cell lineages, (e.g., Map5 which can be expressed in both neurons and glia); thus, in some cases, levels 2 and 3 can be overlapping. 'Neurogenesis' (level 4) is considered when the newly generated cells can be attributed to a well known neuronal (or glial) subtype.

\section{Regional extension of neurogenesis}

The goal of the present paragraph, rather than add new evidence for neurogenesis in non-neurogenic regions, is to update the list by critically discussing the results reported in different mammalian species / brain regions, and by taking into account different criteria that include both technical and scientific considerations (Table 1; Figs 4 and 5).

\section{Neocortex}

Pioneer studies in the search for adult neurogenesis in the mammalian neocortex were those of Michael S. Kaplan (1981), performed by combining thymidine autoradiography and electron microscopy in the 3-month-old rat visual cortex after exposure to a complex environment. At that time, however, it was viewed with scepticism (Kaplan, 2001). More than 20 years later, Dayer et al. (2005) clearly showed the occurrence of new neurons in the deep layers of the rat cerebral cortex. By labelling newlyborn cells with multiple intraperitoneal (i.p.) injections of 5-bromo-2'-deoxyuridine (BrdU), and using markers of both immature and mature neurons to characterize the new cells through a detailed confocal analysis at different survival times, they demonstrated genesis of new $\gamma$-aminobutyric acid (GABA)ergic interneurons 
(level 4, Table 1) in both the neocortex and striatum. At 4-5 weeks survival time, $0.4 \pm 0.13 \%$ of the BrdU+ cells were mature NeuN+ neurons (33 on 7624 cells examined in 10 animals, four sections / animal) in the neocortex. Morphological and phenotypical analyses assert these cells belong to different categories of cortical interneurons. Interestingly, although several BrdU+ $/$ DCX+/Tuc4+ neuroblasts were identified close to the SVZ periventricular region, the great majority of cortical BrdU+ cells (nearly $90 \%$ at 2-h survival time, and $60 \%$ at $4-5$ weeks) were positive for nerve/glial antigen 2 proteoglycan $(\mathrm{Ng} 2)$. From these data the authors suggested that adult cortical newborn interneurons might originate from in situ progenitors. Other studies, also carried out on the rat neocortex, yet less accurate than Dayer's work (Gould et al., 2001; Tamura et al., 2007), support the occurrence of neurogenic events in this region (levels 2 and 3, Table 1). Interestingly, Tamura and colleagues found that a subpopulation of $\mathrm{Ng} 2+/ \mathrm{DCX}+$ cells resides in the rat neocortex, some of which acquire neuronal specification. Neuronal progenitor cells expressing Ki67, BrdU and the mitotic phosphorylated amino-terminal form of the histone H3 (PHH3) proliferation markers have been described in layer 1 of adult rats (Ohira et al., 2010). They also express molecular markers of cells deriving from the ganglionic eminence (Nkx2.1) and GAD67, and increase 1.56-fold after mild ischaemia (see below). Unlike rats, no clear evidence of constitutive neurogenesis has been shown in the intact mouse cerebral cortex, while a few studies indicated the presence of new cells expressing generic markers of mature neurons (NeuN) in the adult neocortex of different monkey species (Gould et al., 1999, 2001; Bernier et al., 2002; Table 1). Gould et al. (1999), by multiple BrdU injections (i.p. and intraventricular, i.v.), showed the addition of newborn neurons in the prefrontal, inferior temporal and posterior parietal cortex of Macaca fascicularis. Surprisingly, they found that 1 week or more after the last BrdU injection in the prefrontal cortex, the majority (62-84\%) of newborn cells showed neuronal features, and a subset of the latter expressed markers of both immature and mature neurons (levels 1-3, Table 1). Further evidence that some new cells were neurons was supported by the presence of newborn cells retrogradely filled with Fluoro-Emerald and/or Fast-Blue previously injected in target areas in which BrdU+ cells had been found. As to the origin, the authors suggested newborn cortical neurons migrate from the SVZ, but no clear evidence supports this hypothesis. A couple of years later, Gould and collaborators reconfirmed the presence of new neurons in the primate neocortex by comparing the production and survival of adult-generated neurons and glia in the dentate gyrus, prefrontal cortex and inferior temporal cortex (Gould et al., 2001). At long survival times they also showed newborn $\mathrm{BrdU}+/ \mathrm{NeuN}+$ cells in the rat neocortex, asserting that adult neurogenesis in this region is not limited to primates.

Besides Old World monkeys (Macaca fascicularis), neurogenesis was described in diverse cortical and subcortical regions (i.e. amygdala, piriform cortex and adjoining inferior temporal cortex) of New World monkeys (Saimiri sciureus; Bernier et al., 2002). In both species newborn neurons expressed the anti-apoptotic protein Bcl-2, and were found distributed along a pathway that extended from the tip of the temporal ventricular horn to the deep portion of the temporal lobe. Data obtained studying the distribution of the BrdU+ cells and performing DiI injections were indicative of the existence of a temporal migratory stream, but a clear demonstration that newborn neurons in the 
temporal lobe may have migrated from the SVZ is still lacking. Their quantitative estimates indicated the impressive result that at least $27 \%$ of BrdU+ cells scattered in the temporal lobe (including the deep layers of temporal cortex) differentiate into neurons.

It is important to highlight that, in contrast to these results, several reports confirmed the presence of proliferating cells in the neocortex of adult macaque monkeys, but such activity was not found associated with the genesis of new neurons (Nowakowski \& Hayes, 2000; Kornack \& Rakic, 2001; Koketsu et al., 2003; Rakic, 2006). Accordingly, by using a new approach based on the carbon-14 (14C) assay to check the age of cells in humans, Bhardwaj et al. (2006) added evidence that neocortical neurogenesis is restricted to a precise developmental stage in the adult human brain. Thus, the presence of neurogenesis in the mammalian neocortex under physiological conditions remains controversial, at least in some species.

By contrast, under experimental induction, neocortical neurogenesis has been identified in virtually all species examined so far - rats, mice and monkeys. In rats, as mentioned above, by injecting into layer 1 a recombinant retrovirus vector expressing membrane-targeted green fluorescent protein (GFP) under the CMV promoter, Ohira et al. (2010) were able to show that proliferating cells that settled in the rat neocortical layer 1, under a mild ischaemic condition, can generate GABAergic cells that migrate to the deep cortical layers within 7-10 days after treatment. At 4 weeks after ischaemia they found several immature and mature neuronal markers expressed in GFP+ cells located between layers 2 and 6 (from 46 to 77\%). In addition, they also showed that about $70 \%$ of GFP+ cells expressed sodium channels essential for the production of action potential and synapsin 1, thus supporting these cells actually differentiating into neurons. Further phenotypic examination of GFP+ cells up to 8 weeks post-ischaemia indicated they differentiated into diverse types of GABAergic neurons. Only a few GFP+ cells of layers 2-6 were found co-labelled for glial markers. Finally, when the virus was injected into the SVZ, a few GFP+ cortical neurons were found, indicating that the large majority of cortical newborn neurons originated from layer 1. Actual integration into preexisting circuits (level 5, Table 1) was suggested based on c-fos expression in GFP newborn neurons in the barrel cortex, after exploration tasks involving the whisker system.

Induction of neurogenesis was also described in the neocortex of adult mice. Two studies performed by the same group (Magavi et al., 2000; Chen et al., 2004), by using synchronous apoptotic degeneration of neurons in layer IV and $\mathrm{V}$, showed the astonishing result of inducing in situ newborn neurons able to form new corticothalamic and corticospinal connections (levels 1-5, Table 1 ). These results asserted that the adult murine cortex, which is nonneurogenic in the intact animals, is capable of neuronal regeneration by activating endogenous progenitors in response to specific forms of injury and under appropriate conditions. Unfortunately, no other studies confirmed these results, which is probably due to the fact that chromophore-targeted laser photolysis is a rather complex methodology.

Newborn neurons have also been found in the sensorimotor cortex of Macaca fascicularis following cervical dorsal rhizotomy (Vessal \& Darian-Smith, 2010; level 4, Table 1). In a previous study, using the same experimental paradigm, they showed reactive neurogenesis in the spinal dorsal horn 6-8 weeks after the lesion (Vessal et al., 2007). These data are interesting as they provide 
evidence that new neurons can be formed within the uninjured cortex in response to a far cervical deafferentation. It is to be noted that analysis of BrdU+ / glial fibrillary acidic protein (GFAP) + cells indicated a significant increase in proliferating astrocytes in the reorganizing cortex, and that no newborn neurons were identified in any cortical region of the control animals. Overall, data seem to support the occurrence of low levels of constitutive neurogenesis in the intact adult neocortex of mammals, with remarkable differences among species. The activity appears more evident in monkeys, while less pronounced in rats and extremely scarce in mice. Interestingly, the low levels of constitutive cortical neurogenesis are substantially increased after a lesion, thus suggesting that this brain region shows some potentialities. Nevertheless, we are reasoning over a restricted number of species analysed so far, wherein most results do not support the occurrence of complete neurogenesis.

\section{Striatum}

A large number of studies have investigated the occurrence of adult neurogenesis in the striatum of mammals, especially in rodents and in neurodegenerative models (Emsley et al., 2005). Under physiological conditions the occurrence of cells expressing molecular markers of neural plasticity such as PSA-NCAM and DCX were initially described in the striatum of both mice (Yang et al., 2004) and rats (Nacher et al., 2001). In these studies, some of these cells were found to show morphological features of migrating neuroblasts (Yang et al., 2004), and other characteristics of mature neurons (Nacher et al., 2001; Yang et al., 2004).

Later on, the above-mentioned study performed by Dayer et al. (2005) suggested that in rats these cells could be potentially considered as part of an adult neurogenic process leading to the genesis of striatal interneurons. Indeed, by examining the expression of immature and mature neuronal markers in the striatal periventricular region at different BrdU post-injection survival times, they found newborn cells progressively undergoing neuronal specification and differentiation into GABAergic interneurons (levels 1-4, Table 1). At 4-5 weeks survival time, about $6 \%$ of the BrdU+ striatal cells (57/ 995 cells identified examining two sections in eight animals) expressed NeuN, and the vast majority were positive for calretinin (which in the striatum characterizes a small subpopulation of interneurons). These cells were mostly found in the nucleus accumbens and within the dorso-medial striatum, the latter corresponding to the caudate nucleus in non-rodent mammals.

Interestingly, in contrast to newborn cortical cells described in the same study (see above), striatal newborn neurons were suggested as originating from the adjacent SVZ.

Less detailed studies indicating lower levels of neurogenesis were performed in the striatum of intact mice and monkeys (Table 1). In monkeys, BrdU was associated with the mature neuronal marker NeuN, at long survival times (Bédard et al., 2002a, 2006). By contrast, a neurogenic system acting under physiological conditions was described in the caudate nucleus of adult rabbits (Luzzati et al., 2006). Newborn BrdU+ cells were associated with multiple immature and mature markers of neurons (levels 1-4, Table 1). The stereological time course analysis indicated that BrdU+/NeuN+ cells were only detectable at the longer survival times considered, and that after 2 
months only $0.7 \%$ of the surviving BrdU+ cells were detectable as newborn neurons. Additional confocal phenotypic analyses indicated that about $1 / 6$ of newly formed neurons differentiated into calretinin striatal interneurons (Fig. 6). In spite of an extremely low number of newly formed interneurons, if 

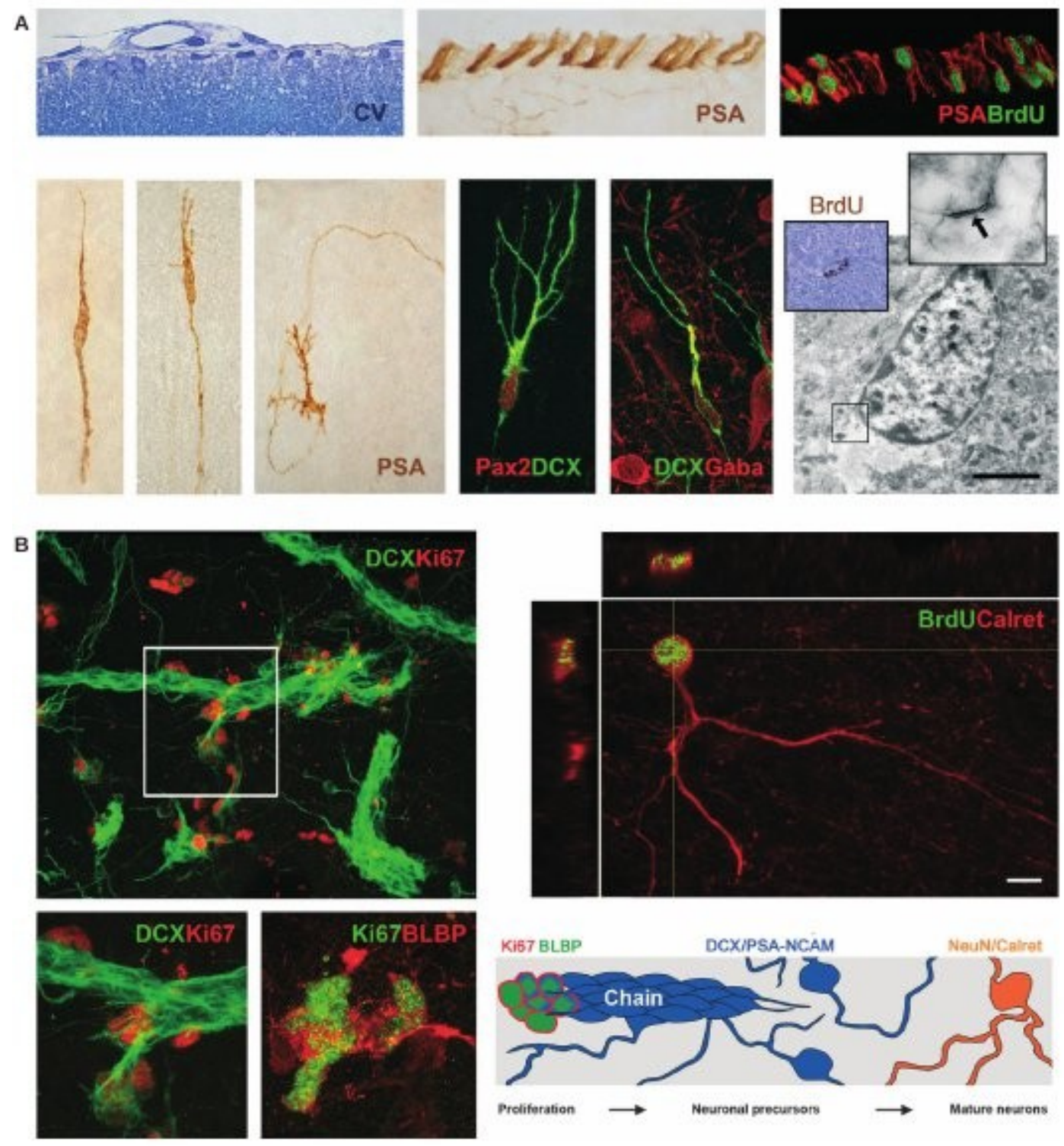

Fig. 6. Species-specific peripubertal and adult neurogenesis in rabbits. (A) Cerebellum; (B) striatum. The rabbit cerebellum is an example of protracted neurogenesis extending into adulthood, although with decreasing intensity. A SPL (A, top) is detectable on the cerebellar surface until puberty as an extension of the early postnatal external granule layer. Pax $2+, \gamma$ aminobutyric acid (GABA)ergic interneurons continue to be generated in the cerebellar cortex of young / adult rabbits, at least up to 3 years old (A, bottom). BLBP, brain lipid-binding protein; BrdU, 5-bromo-2'-deoxyuridine; CV, Cresyl violet; DCX, doublecortin; PSA, highly polysialylated form of the neural cell adhesion molecule; the electron microscopy images are referred to pre-embedding detection of a BrdU + cell 60 days post-injection. The rabbit striatum (B) is an example of persistent neurogenesis (investigated until 3 years old without any decrease in the rate of cell genesis) occurring from BLBP+ local progenitor division then giving rise to chains of DCX+ neuroblasts and Calretininin (Calret)+ neurons in the caudate nucleus. Both these neurogenic processes originate from local parenchymal progenitors independently from protracted/persistent germinal layers, and are absent in rodents. (A) From Ponti et al. (2006b, 2008); (B) from Luzzati et al. (2006).

referring to the whole striatal calretinin population, the percentage of newly generated calretinin cells is not negligible, as it represents about $0.1 \%$. These results support constitutive neurogenesis in this region, partly devoted to 
replace and / or add cells within the small subpopulation of calretinin striatal interneurons. Comparison with the SVZ-olfactory bulb system and hippocampus, wherein about $50 \%$ of the neuronal precursors became mature neurons (Petreanu \& Alvarez-Buylla, 2002; Kempermann et al., 2004), indicates that neuroblast survival within the adult caudate nucleus is very low ( $<10 \%$ of the initial neuronal precursor population). On the other hand, similarly to the SVZ-olfactory bulb system, striatal neuronal precursors are initially organized as chains, which in turn give rise to individual elements that ultimately differentiate into mature NeuN-positive neurons (Fig. 6). As to the origin of these cells in the striatum, by using the endogenous marker of cell proliferation Ki67 it was shown that part of the striatal proliferating cell population is organized into small clusters mainly distributed in the medialdorsal part of the striatum. Quantitative studies and confocal analyses on thick sections demonstrated a close physical and numerical correlation between the number of striatal chains and proliferating clusters, suggesting that striatal neuronal precursors originate locally from the activity of proliferating cells, which act as amplifying elements (Fig. 6). Genesis of neuroblasts directly from the mature striatal parenchyma was confirmed in vitro by culturing small strips of tissue obtained from the striatum. In addition, phenotypic analyses indicated that about $85 \%$ of the proliferating clusters express the astroglial marker brain lipid-binding protein (BLBP), a protein abundant in radial glia, which serve as neuronal progenitors in all regions of the CNS and give rise to the adult SVZ and SGZ progenitors (Anthony et al., 2004). It is interesting to note that ongoing studies on the striatum of young / adult guinea pigs (Luzzati et al., 2011) indicate the occurrence of a similar neurogenic system.

While data regarding experimentally induced neurogenesis in the rabbit and monkey are still lacking, as mentioned beforehand, a huge number of studies have investigated striatal neurogenesis in rodent models of neuronal degeneration. The Swedish group of Olle Lindvall examined in detail strokeinduced neurogenesis in the rat striatum. After transient ischaemia they found that SVZ precursors migrated to the more severely injured areas of the striatum, where they differentiate into mature neurons (Arvidsson et al., 2002; levels 1-4, Table 1). Indeed, at 4-weeks survival time, they identified many $\mathrm{BrdU}+/ \mathrm{NeuN}+$ cells. Interestingly, newborn NeuN+ neurons were not identified in the injured regions of the parietal cortex. Accordingly, at 5 weeks following the insult they found that about $42 \%$ of $\mathrm{BrdU}+/ \mathrm{NeuN}+$ cells also expressed DARPP-32, a marker characterizing the mature striatal projection neurons. Other reports described similar results in mice models of striatal neurodegeneration (Yamashita et al., 2006; Cho et al., 2007), suggesting that under certain circumstances, and particularly after growth factor infusions (Pencea et al., 2001; Teramoto et al., 2003; Cho et al., 2007), reactive neurogenesis in rodents can regenerate a few lost striatal neurons. Nevertheless, Liu et al. (2009), by combining BrdU and viral labelling with multiple markers, demonstrated that ischaemic injury in rats does not alter the intrinsic differentiation of SVZ neuroblasts migrating to the lesioned striatum, thus suggesting in this case that reactive neurogenesis involving activation of SVZ progenitors is mostly abortive. These contradictory results raise a question about the possible activation of latent parenchymal progenitors, a hypothesis that has been a lot less investigated in striatal injury-induced neurogenesis. 
Constitutive neurogenesis in the adult striatum is a striking example of remarkable differences among mammalian species, ranging from absence in mice to occurrence of a robust neurogenic system in rabbits. On the other hand, substantial induction of neurogenesis has been described to occur in rodents after different types of lesion, whereas no data are currently available on species endowed with spontaneous striatal neurogenesis (rabbits). Overall, the striatum of mammals appears as an unfavourable environment for survival rather than genesis of newly formed neurons.

\section{Hypothalamus}

Since 2005, several publications based on experiments carried out on rodents have been reporting data on the hypothalamus as a new site for adult constitutive neurogenesis in mammals (for review, see Migaud et al., 2010). Under physiological conditions, both in rats (Xu et al., 2005) and mice (Kokoeva et al., 2007; Bennett et al., 2009), proliferative activity does occur in the ependymal layer of the third ventricle and within the surrounding parenchyma. In rats, $\mathrm{Xu}$ and collaborators using electron microscopy and immunohistochemistry showed that tanycytes lining the 3rd ventricle proliferate and express molecules usually found in glial, stem-like progenitor cells, such as BLBP and nestin. The presence of putative neural progenitors was further supported by the isolation of cells able to give rise to neurospheres from the hypothalamus. One month after BrdU injection, proliferating cells, some of which expressing Hu protein, were detected in the surrounding parenchyma. Similar results were obtained in mice (Kokoeva et al., 2007), yet in both rodent species no clear evidence has supported constitutive and complete hypothalamic adult neurogenesis under physiological conditions. A significant increase in hypothalamic proliferating cells can be obtained by performing i.v. delivery of BrdU (350\% more positive nuclei, in comparison to i.p. treated animals); nevertheless, in spite of such cell proliferation the level of neurogenesis in the intact hypothalamus seems to be arrested at a very premature stage (level 1, Table 1). On the other hand, growth factor infusion (Pencea et al., 2001; Kokoeva et al., 2005; Xu et al., 2005; Pérez-Martı 'n et al., 2010) or certain experimental conditions / models, such as prolonged heat exposure (Matsuzaki et al., 2009) and the mutant mice investigated by Pierce \& Xu (2010; see below), seem to increase neurogenesis in the hypothalamus. Intracerebroventricular infusion of insulin growth factor I in rats (Pérez-Martín et al., 2010) triggered an intense proliferation along the 3rd periventricular area and in the parenchyma of the caudal hypothalamus. As concerns the genesis of new neurons, after i.v. treatment with bFGF in rats (Xu et al., 2005), and ciliary neurotrophic factor (CNTF) in mice (Kokoeva et al., 2005), it was shown that proliferation induced by growth factors can be followed by genesis of newborn neurons (levels 1-3, Table 1). In addition, after CNTF infusion, some of the newborn (induced) hypothalamic neurons were found to express the phosphorylated form of STAT3, a component of the leptin-activated signalling cascade that plays a key role in the control of feeding centres (Bates et al., 2003). Interestingly enough, in a mouse model showing progressive degeneration of the hypothalamic arcuate nucleus neurons expressing orexigens, proliferation increases and newborn cells seem to regenerate lost neurons (Pierce \& Xu, 2010). Because acute elimination of these neurons leads to severe anorexia 
and weight loss, while progressive elimination does not, it has been proposed that such reactive neurogenesis could act as a true compensatory mechanism. Detailed morphological and molecular analyses of the 3rd periventricular region of these animals showed interesting architectural similarities with the SVZ neurogenic niche (e.g. proliferating astroglial cells contacting the ventricle by an apical process bearing a single cilium), with tanycytes as primary proliferating elements lining the 3rd ventricle (Pérez-Martı́ $n$ et al., 2010). Yet, additional studies are necessary to clearly demonstrate/confirm whether hypothalamic newborn neurons generated after physiological/ pathological stimulation actually become part of the pre-existing circuits playing a role in energy-balance mechanisms. On the whole, the data gathered concerning hypothalamic putative neurogenesis suggest the existence of low basal levels of cell genesis, associated with striking potentialities for reactive neurogenesis, most of which remain incomplete.

\section{Cerebellum}

The mammalian cerebellum, as a typical example of postnatal neurogenesis aimed at establishing a huge population of granule cells during the period in which the animal is interacting with the external environment, is treated in more detail in the paragraph on protracted neurogenesis.

The cerebellum is also a remarkable model for adult neurogenesis regionalization among mammals. Until a few years ago, it was universally accepted that all processes of delayed cell genesis in the neuronal lineage were exhausted with the end of granule cell genesis and concurrent EGL disappearance (Altman, 1972). Yet, two studies carried out on rabbits revealed substantial genesis of cerebellar interneurons until peripubertal ages, and to a lesser extent, in adult animals (Ponti et al., 2006b, 2008). These cells are Pax2+ neuroepithelial-derived neurons (Weisheit et al., 2006) that continue to proliferate within the cerebellar cortex parenchyma in the absence of any residual germinal layers (Ponti et al., 2008, 2010). This neurogenic process occurs spontaneously in the intact rabbit CNS and in parallel with the proliferation of microtubule-associated protein 1B (Map5+) glia-like cells showing the same morphology and distribution of $\mathrm{Ng} 2+$ cells in rodents. The newly generated Pax2+ interneurons were followed by BrdU injection and long-term survival (2 months); they also express PSA-NCAM and DCX during the first 3 weeks after birth, thus revealing their morphology of bipolar, migratory cells, which is followed by a typical neuronal morphology, being GABA positive, and negative for Sox2 and Olig2 (Ponti et al., 2008). Hence, rabbit cerebellar neurogenesis can be placed at level 4 . We know the cellular source, but it is not clear if cell divisions occur either within the white matter or the cerebellar cortical grey matter (the first BrdU+ /PSA-NCAM+ cells are detectable 5 days after injection; Ponti et al., 2008), although the occurrence of bipolar double-stained cells suggests they could come from the white matter. Both the newborn cell populations were identified with pre-embedding electron microscopy (BrdU, 2 months after injection); however, apart from scattered synaptic figures their fate within the cerebellar tissue remains obscure.

Under the comparative profile, the rabbit cerebellar neurogenesis appears as a unique example of adult constitutive neurogenesis in mammals whose functional meaning remains obscure. Its decreasing rate should incorporate it 
into the protracted neurogenic processes, although the widespread addition of neuronal precursors in the adult occurs beyond the end of cerebellar morphogenesis.

\section{Other parenchymal regions}

Different levels of neurogenesis were reported in other 'non-neurogenic regions' of the adult mammalian brain (Table 1). For instance, under physiological conditions newborn neuroblasts were detected in the amygdala of both monkeys (Bernier et al., 2002) and rabbits (Luzzati et al., 2003). Similarly, hints of neurogenesis were described within the piriform cortex of rodents (Pekcec et al., 2006; Shapiro et al., 2007) and monkeys (Bernier et al., 2002), in the olfactory tubercle of mice (Shapiro et al., 2007) and monkeys (Bédard et al., 2002b), in the dorsal vagal complex of the rat brainstem (Bauer et al., 2005), in the Hammon's horn of hippocampus (Rietze et al., 2000) and in the substantia nigra of mice (Zhao et al., 2003; Zhao \& Janson Lang, 2009). In the latter studies, dopaminergic neurons of the substantia nigra pars compacta were thought to continuously generate during adulthood. Due to the direct involvement of these cells in Parkinson's disease, this result raised new perspectives for investigating such a severe neurodegenerative pathology. Progenitor cells with neurogenic potential in vitro had previously been detected in the adult substantia nigra of rats (Lie et al., 2002), however, it is to be noted that no such studies were confirmed/performed in other mammalian species, and no evidence for new dopaminergic neurons were obtained in investigations performed in other laboratories (Frielingsdorf et al., 2004).

In some studies the occurrence of newborn neurons in non-neurogenic regions was correlated with the periventricular germinative region lining the lateral ventricles (i.e. migration of neuroblasts from the SVZ). By contrast, SVZindependent neurogenesis was hypothesized in the brainstem of rats (from the 4th ventricle floor; Bauer et al., 2005), in the Hammon's horn of the hippocampus (local parenchyma; Rietze et al., 2000) and in the substantia nigra of mice (from midbrain periaqueductal region; Zhao et al., 2003; Zhao \& Janson Lang, 2009). In rats, after ischaemic brain injury and growth factor infusion, Nakatomi et al. (2002) showed massive regeneration of hippocampal pyramidal neurons. Functionally integrated newborn neurons were described with different techniques, including electrophysiology, and a certain behavioural recovery was reported (levels 1-5, Table 1). This striking result, similar to that obtained by the group of Macklis in the mouse neocortex, would suggest that endogenous progenitors could regenerate lost neurons under specific stimuli, yet also in this case the study remains a nonreproducible 'broken promise'. On the whole, in most of the above-mentioned studies no clear information was provided as to the source and location of progenitors giving rise to neurogenesis.

\section{Gliogenesis (and neurons from glia?)}

Although the main focus of this review is on the genesis of neurons, many recent developments concerning parenchymal neural progenitors deal with glia or glia-like cells (reviewed in Nishiyama et al., 2009; Boda \& Buffo, 2010; Trotter et al., 2010; Robel et al., 2011). In addition, we are focusing on 
parenchymal neurogenesis in the so-called non-neurogenic regions, which turns out to be mostly gliogenic. In the past, neurogenesis and gliogenesis had always been kept separate, the latter being considered less important than the former. Yet, in recent years, adult gliogenesis has been re-evaluated as many populations of progenitor cells with glial-like features and proliferative capacities have been shown to exist in the mature CNS. A number of in vivo studies clearly showed that different types of these progenitor cells are widely present in white and grey matter of the mature CNS (reviewed in Nishiyama et al., 2009). Some of these progenitors ensure a slow process of gliogenesis leading to renewal of oligodendrocytes and, to a lesser extent, astrocytes (Horner et al., 2000; Nishiyama et al., 2009; Boda \& Buffo, 2010), which could be considered as constitutive gliogenesis. In mice, most of these cells express $\mathrm{Ng} 2$ and are morphologically, antigenically, functionally distinct from mature astrocytes, oligodendrocytes and microglia (Horner et al., 2002; Butt et al., 2005; Nishiyama et al., 2009). They are also called 'polydendrocytes' or 'synantocytes', coexpress platelet-derived growth factor $\alpha$ (PDGFR $\alpha)$, Olig2, Sox10, and are considered the main source of adult constitutive gliogenesis (Horner et al., 2002; Trotter et al., 2010). Beside this activity, it has been reported that some neurons generated in different cortical areas of young / adult rodents can originate from $\mathrm{Ng} 2+$ cells (Dayer et al., 2005; Tamura et al., 2007; Guo et al., 2010). Some Ng2+/PDGFR $\alpha+$ progenitor cells in the piriform cortex also express low levels of DCX, Sox2 and Pax6. By using genetic fate-mapping with an inducible Cre-LoxP recombination they were shown to differentiate into pyramidal neurons (Rivers et al., 2008; Guo et al., 2010). The hypothesis that some glial cells, including astrocytes, can somehow retain multipotential properties (radial glia-like features) in the adult derives from the observation that in other vertebrates, such as fish, amphibians and reptiles, a class of glial cells known as radial ependymoglia persists in several CNS regions sustaining regeneration (reviewed in Grandel et al., 2006; Bonfanti, 2011). In mammals, most of the radial glia-derived parenchymal astrocytes lose these properties early after birth (Laywell et al., 2000), and only a subset of SVZ/SGZ astrocytes behave as stem cells (Kriegstein \& Alvarez-Buylla, 2009). Nevertheless, some parenchymal progenitors show multipotentiality when isolated in vitro, although they do not perform 'actual' neurogenesis in vivo (Palmer et al., 1995, 1999; Nishiyama et al., 2009; Boda \& Buffo, 2010). Due to the fact that reactive glial cells can re-express many markers of immature glia, the hypothesis was made that they could be reprogrammed to generate neurons (Robel et al., 2011). This goal has currently been achieved in vitro, whereas many controversies remain open as far as in vivo studies are concerned. Several authors that generated different transgenic mice to target the $\mathrm{Ng} 2+$ cells failed to show any differentiative fate other than oligodendrocytes, both in the normal and damaged brain (Dimou et al., 2008; Zhu et al., 2008; Kang et al., 2010; Tripathi et al., 2010). Yet again, similarly to what was previously discussed concerning neurogenesis, these discrepancies could be attributable to technical reasons (differences in the specificity of Cre-targeting to $\mathrm{Ng} 2$ cells and the efficacy of Cre induction may contribute to the different results obtained), and to heterogeneity in the distribution/type of progenitors in different CNS regions and animal species. Gliogenesis in particular, and its hypothetical derived capability to generate neurons, could be heterogeneous due to differences in progenitor cell populations / subpopulations (mostly not yet identified; see Fig. 5) dispersed at 
diverse CNS locations (Trotter et al., 2010). An example can be given by $80 \%$ of $\mathrm{Ng} 2+$ cells, which seem to mature into oligodendrocytes in adult mouse white matter, whereas only $20 \%$ in grey matter (Dimou et al., 2008).

Alternatively, heterogeneity could be explained by the occurrence of cells displaying ill-defined antigenic features due to different differentiative stages. Indeed, one of the problems encountered in this type f study relies on the

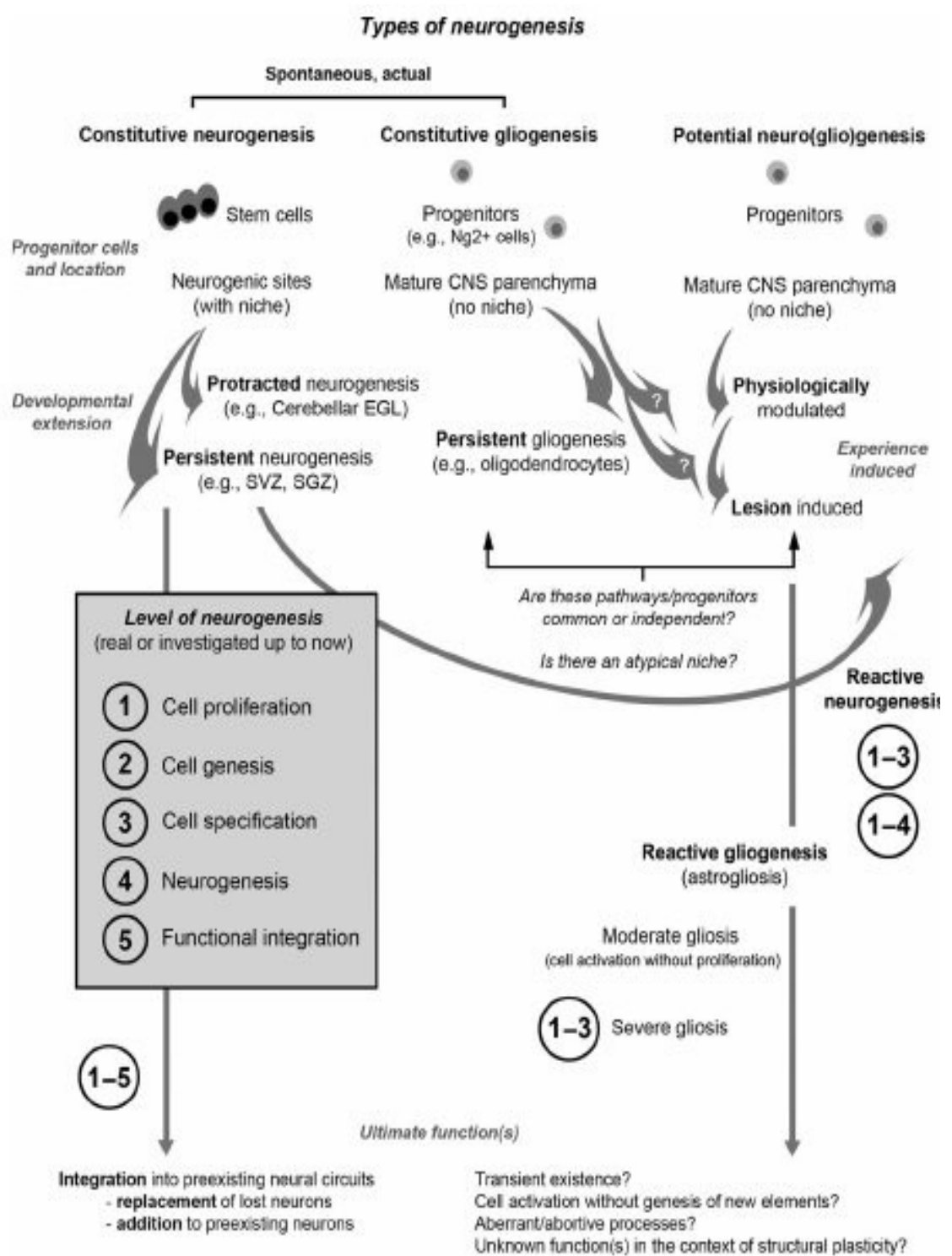

Fig. 7. Summary of the different aspects implicated in shaping adult neurogenesis in mammals, and some of their interplay. Differences among mammalian species are more pronounced in parenchymal neurogenesis (top, right). EGL, external germinal layer; Ng2, nerve/glial antigen 2 proteoglycan; SGZ, subgranular zone; SVZ, subventricular zone.

on the fact that some of the markers used to visualize neural parenchymal progenitors can overlap in cell populations belonging to different lineages or can be expressed by cells during transient differentiative states. The progenitors described by Guo et al. (2010), similarly to some cells in the adult rat neocortex (Tamura et al., 2007), do express concurrently Ng2 and low levels of DCX, namely two markers that are usually associated with subsets of glial and neuronal cells, respectively. Furthermore, the Map5 antigen, which reveals the multipolar Olig2 + cells of the rabbit parenchyma (Ponti et al., 2008; see above) and is highly expressed in glial cells such as 
oligodendrocytes and Schwann cells (Fischer et al., 1990; Ma et al., 1999; Wu et al., 2001), is also detectable in many neuronal cell populations of the developing and mature peripheral nervous system and CNS (Schoenfeld et al., 1989; Nothias et al., 1996). In the context of gliogenesis, the picture is complicated by the existence of the activation of molecular pathways, with no cell proliferation. The swelling and increased synthesis of cytoskeletal components observed in astrogliosis is a striking example. Similarly, several classes of neurons retain expression of immature cell-related molecules (PSANCAM, DCX) not being newly generated. Such antigenic ambiguity/ heterogeneity could be a simple variability in the cell molecular composition, yet it might also be related to a real multipotentiality manifested by some parenchymal progenitors in vivo. Under an inter-mammalian comparative profile, another possible explanation for antigenic heterogeneity can reside in species-specific differences. Little is known about species-specific related differences involving these glia-like cells in mammals, nevertheless $\mathrm{Ng} 2+$ cells are not detectable in rabbits (which may simply be due to a different epitope recognized by antibodies; Ponti et al., 2008) and Map5+ multipolar cells are not present in the brain or cerebellum of rodents, although they are detectable in cats (Paola Crociara \& Luca Bonfanti, unpublished data).

\section{Concluding remarks and future perspectives}

Results obtained during the last two decades revealed many examples of adult neurogenesis in different mammalian brain regions and species. The analysis of protracted and adult neurogenesis in the intact and lesioned CNS parenchyma of mammals remains far from being complete, particularly in the large-sized, hardly accessible human brain. Results are fragmentary as they come from scattered, yet time-consuming experimental analyses, due to the obvious limitations encountered - large brain size, scant availability of specimens, extended individual lifespan, ethical concerns, etc. Other limits simply consist of the fact that comparative analyses do not embrace all mammals, or that in some species / brain regions, the available data are restricted either to physiological states or to lesion paradigms.

Notwithstanding these difficulties, substantial information is now available to draw some conclusions that could be 'transversal' in mammals. First of all, three groups of neurogenic regions can be roughly distinguished - (i) those substantially constant in different species and displaying constitutive, complete neurogenesis in germinal layer-derived neurogenic sites (SVZ, SGZ); (ii) those relatively constant in different species yet manifesting widely different degrees of neurogenesis depending on the species (e.g. striatum and cortex); and (iii) those showing either the absence or presence of neurogenesis depending on the species (e.g. the cerebellum in rodents and rabbits).

Any generalization is hampered by the different aspects that neurogenic processes can show in different CNS regions/species (summarized in Fig. 7). Two main types of neurogenesis occur in the mammalian CNS - a 'complete' neurogenesis, substantially limited to SVZ and SGZ neurogenic sites; and a rather 'incomplete' neurogenesis, generally occurring in the parenchyma (non-neurogenic regions). From a comparative analysis of neurogenesis in different mammalian species and CNS regions, complete neurogenesis, i.e. fulfilling all the five subsequent steps or levels defined in Fig. 4 and Table 2, is 
shown to be hardly detectable in parenchymal regions. This fact can be surely linked to its low rate and widespread, disseminated distribution, but also suggests the possibility that its biological role and significance might be different from the one in typical hippocampal/olfactory bulb neurogenesis. In other words, the possibility that some of these neurogenic processes cannot be aimed at neuronal replacement/addition as do their counterpart in neurogenic sites should also be taken into account.

The incomplete, parenchymal neurogenesis can often be latent/quiescent in the intact nervous tissue, yet remarkably inducible/increased in experimental / pathological situations. In this context, there is indirect evidence that such potential/reactive neurogenesis preferentially manifests in the parenchymal regions that maintain some constitutive, spontaneous neurogenic processes. Whether the differences underlining the heterogeneity of adult neurogenic processes are attributable either to the occurrence/type of progenitors or to tissue-specific environmental cues remains to be determined. Surely, most examples of spontaneous parenchymal neurogenesis indicate that a latent and / or 'low-level' neurogenic program does exist, although with the differences described herein. Nevertheless, it cannot be expressed in a successful way in mammals, as it is quite clear that mobilization of neural progenitors is insufficient and inefficient to grant CNS regeneration/healing in mammals, as it is quite clear that mobilization of neural progenitors is insufficient and inefficient to grant CNS regeneration/healing of 'caution' in assessing the occurrence of neurogenesis in mammals (both technically and biologically) should not be necessarily intended in a critical/restrictive perspective. In those cases in which a clear discrepancy actually exists between the technical approach used, the data obtained and the conclusive speculations, a rigorous critical attitude should be adopted. On the other hand, by viewing the results from a biological rather than technical perspective, the incapability of achieving a full demonstration of complete neurogenesis could also hide alternative explanations. In other words, we should look at neurogenic processes in different CNS regions / animal species as a gradient of different degrees and types of plasticity that could have been adapted to different tissue environments and functional demands. This means that adult neurogenesis is one among other forms of CNS structural plasticity (e.g. synaptic remodelling, existence of immature, non-newly generated neurons, etc.), and we lack information concerning how its incomplete expressions in the parenchyma could play a role in the global picture.

In conclusion, to reach more insight into adult mammalian neurogenesis and its possible translational perspective, many questions remain open, such as how extended is constitutive and/or potential neurogenesis in mammals? Does a constitutive parenchymal neurogenesis occur in some mammals? Does a constitutive gliogenesis occur in the CNS parenchyma? Then, when dealing with reactive neurogenesis, a crucial question might be - is the reactive / induced neurogenic process an enhancement of constitutive neurogenesis existing at low, normally undetectable levels (quiescent and potential) or rather is it a de novo activation of specific progenitors responding selectively to different noxious stimuli?

We think that future directions in this field of research should address three main critical questions related to - whether 'atypical' stem cell niches are required to grant the initiation of parenchymal neurogenesis; whether parenchymal neurogenic processes are actually abortive as a consequence of 
the unfavourable CNS tissue environment; and how incomplete neurogenesis is a part or a complement of other forms of CNS structural plasticity.

\section{Acknowledgement}

This work was supported by Compagnia di San Paolo (NEUROTRANSPLANT 2008.2192), Universita` di Torino, Regione Piemonte.

\section{Abbreviations}

BDNF, brain-derived neurotrophic factor; BLBP, brain lipid-binding protein; BrdU, 5-bromo-2'-deoxyuridine; CNTF, ciliary neurotrophic factor; DCX, doublecortin; EGL, external germinal layer; GABA, $\gamma$-aminobutyric acid; GFAP, glial fibrillary acidic protein; GFP, green fluorescent protein; Map5, microtubule-associated protein 1B; $\mathrm{Ng} 2$, nerve/glial antigen 2 proteoglycan; PDGFR $\alpha$, platelet-derived growth factor $\alpha$; PHH3, mitotic phosphorylated amino-terminal form of the histone H3; PSA-NCAM, highly polysialylated form of the neural cell adhesion molecule; RMS, rostral migratory stream; SGZ, subgranular zone; SPL, subpial layer; SVZ, subventricular zone; VMM, ventral migratory mass; VMS, ventrocaudal migratory stream.

\section{References}

Alahmed, S. \& Herbert, J. (2008) Strain differences in proliferation of progenitor cells in the dentate gyrus of the adult rat and the response to fluoxetine are dependent on corticosterone. Neuroscience, 157, 677-682.

Altman, J. (1963) Autoradiographic investigation of cell proliferation in the brains of rats and cats. Anat. Rec., 145, 573-591.

Altman, J. (1972) Postnatal development of the cerebellar cortex in the rat. I. The external germinal layer and the transitional molecular layer. J. Comp. Neurol., 145, 353-397.

Altman, J. \& Das, G.D. (1965) Post-natal origin of microneurones in the rat brain. Nature, 207, 953-956.

Amrein, I. \& Slomianka, L. (2010) A morphologically distinct granule cell type in the dentate gyrus of the red fox correlates with adult hippocampal neurogenesis. Brain Res., 1328, 12-24.

Amrein, I., Dechmann, D.K., Winter, Y. \& Lipp, H.P. (2007) Absent or low rate of adult neurogenesis in the hippocampus of bats (Chiroptera). PLoS ONE, 2 , e455.

Anthony, T.E., Klein, C., Fishell, G. \& Heintz, N. (2004) Radial glia serve as neuronal progenitors in all regions of the central nervous system. Neuron, 41, 881-890.

Arvidsson, A., Collin, T., Kirik, D., Kokaia, Z. \& Lindvall, O. (2002) Neuronal replacement from endogenous precursors in the adult brain after stroke. Nat. Med., 8, 963-970.

Bailey, M.S., Puche, A.C. \& Shipley, M.T. (1999) Development of the olfactory bulb: evidence for glia-neuron interactions in the glomerular formation. J. Comp. Neurol., 415, 423-448.

Barker, J.M., Boonstra, R. \& Wojtowicz, J.M. (2011) From pattern to purpose: how comparative studies contribute to understanding the function of adult 
neurogenesis. Eur. J. Neurosci., 34, 963-977.

Bates, S.H., Stearns, W.H., Dundon, T.A., Schubert, M., Tso, A.W., Wang, Y., Banks, A.S., Lavery, H.J., Haq, A.K., Maratos-Flier, E., Neel, B.G., Schwartz, M.W. \& Myers, M.G. Jr (2003) STAT3 signalling is required for leptin regulation of energy balance but not reproduction. Nature, 421, 856-859.

Bauer, S., Hay, M., Amilhon, B., Jean, A. \& Moyse, E. (2005) In vivo neurogenesis in the dorsal vagal complex of the adult rat brainstem. Neuroscience, 130, 75-90.

Bédard, A., Cossette, M., Levesque, M. \& Parent, A. (2002a) Proliferating cells can differentiate into neurons in the striatum of normal adult monkey. Neurosci. Lett., 328, 213-216.

Bédard, A., Levesque, M., Bernier, P.J. \& Parent, A. (2002b) The rostral migratory stream in adult squirrel monkeys: contribution of new neurons to the olfactory tubercle and involvement of the antiapoptotic protein Bcl-2. Eur. J. Neurosci., 16, 1917-1924.

Bédard, A., Gravel, C. \& Parent, A. (2006) Chemical characterization of newly generated neurons in the striatum of adult primates. Exp. Brain Res., 170, 501-512.

Bennett, L., Yang, M., Enikolopov, G. \& Iacovitti, L. (2009) Circumventricular organs: a novel site of neural stem cells in the adult brain. Mol. Cell. Neurosci., 41, 337-347.

Bernier, P.J., Bédard, A., Vinet, J., Lévesque, M. \& Parent, A. (2002) Newly generated neurons in the amygdala and adjoing cortex of adult primates. Proc. Natl Acad. Sci. USA, 99, 11464-11469.

Bhardwaj, R.D., Curtis, M.A., Spalding, K.L., Buchholz, B.A., Fink, D., Bjo“rkEriksson, T., Nordborg, C., Gage, F.H., Druid, H., Eriksson, P.S. \& Frisén, J(2006) Neocortical neurogenesis in humans is restricted to development. Proc. Natl Acad. Sci. USA, 103, 12564-12568.

Boda, E. \& Buffo, A. (2010) Glial cells in non-germinal territories: insights into their stem/progenitor properties in the intact and injured nervous tissue. Arch. Ital. Biol., 148, 119-136.

Bonfanti, L. (2011) From hydra regeneration to human brain structural plasticity: a long trip through narrowing roads. ScientificWorldJournal, 11, 1270-1299.

Bonfanti, L. \& Ponti, G. (2008) Adult mammalian neurogenesis and the New Zealand white rabbit. Vet. J., 175, 310-331.

Breunig, J.J., Arellano, J.I., Macklis, J.D. \& Rakic, P. (2007) Everything that glitters isn't gold: a critical review of postnatal neural precursor analyses. Cell Stem Cell, 1, 612-627.

Butt, A.M., Hamilton, N., Hubbard, P., Pugh, M. \& Ibrahim, M. (2005) Synantocytes: the fifth element. J. Anat., 207, 695-706.

Chen, J., Magavi, S.S. \& Macklis, J.D. (2004) Neurogenesis of corticospinal motor neurons extending spinal projections in adult mice. Proc. Natl Acad. Sci. USA, 101, 16357-16362.

Chiaramello, S., Dalmasso, G., Bezin, L., Marcel, D., Jourdan, F., Peretto, P., Fasolo, A. \& De Marchis, S. (2007) BDNF/TrkB interaction regulates migration of SVZ precursor cells via PI3-K and MAP-K signalling pathways. Eur. J. Neurosci., 26, 1780-1790.

Cho, S.R., Benraiss, A., Chmielnicki, E., Samdani, A., Economides, A. \& Goldman, S.A. (2007) Induction of neostriatal neurogenesis slows disease progression in a transgenic murine model of Huntington disease. J. Clin. 
Invest., 117, 2889-2902.

Clark, P.J., Kohman, R.A., Miller, D.S., Bhattacharya, T.K., Brzezinska, W.J. \& Rhodes, J.S. (2011) Genetic influences on exercise-induced adult hippocampal neurogenesis across 12 divergent mouse strains. Genes Brain Behav., 10, 345-353.

Charvet, C.J. \& Striedter, G.F. (2011) Causes and consequences of expanded subventricular zones. Eur. J. Neurosci., 34, 988-993.

Conover, J.C., Doetsch, F., Garcia-Verdugo, J.M., Gale, N.W., Yancopoulos, G.D. \& Alvarez-Buylla, A. (2000) Disruption of Eph/ephrin signaling affects migration and proliferation in the adult subventricular zone. Nat. Neurosci., 3, 1091-1097.

Cooper-Kuhn, C.M. \& Kuhn, H.G. (2002) Is it all DNA repair? Methodological considerations for detecting neurogenesis in the adult brain. Brain Res. Dev. Brain Res., 134, 13-21.

Curtis, M.A., Kam, M., Nannmark, U., Anderson, M.F., Axell, M.Z., Wikkelso, C., Holtas, S., van Roon-Mom, W.M., Bjork-Eriksson, T., Nordborg, C., Frisen, J., Dragunow, M., Faull, R.L. \& Eriksson, P.S. (2007) Human neuroblasts migrate to the olfactory bulb via a lateral ventricular extension. Science, 315, 1243-1249.

Curtis, M.A., Kam, M. \& Faull, R.L. (2011) Neurogenesis in humans. Eur. J. Neurosci., 33, 1170-1174.

Danilov, A.I., Gomes-Leal, W., Ahlenius, H., Kokaia, Z., Carlemalm, E. \& Lindvall, O. (2009) Ultrastructural and antigenic properties of neural stem cells and their progeny in adult rat subventricular zone. Glia, 57, 136-152 .

Dayer, A.G., Cleaver, K.M., Abouantoun, T. \& Cameron, H.A. (2005) New GABAergic interneurons in the adult neocortex and striatum are generated from different precursors. J. Cell Biol., 168, 415-427.

De Marchis, S., Fasolo, A. \& Puche, A.C. (2004) Subventricular zone-derived neuronal progenitors migrate into the subcortical forebrain of postnatal mice. J. Comp. Neurol., 476, 290-300.

Dimou, L., Simon, C., Kirchhoff, F., Takebayashi, H. \& Götz, M. (2008) Progeny of Olig2-expressing progenitors in the gray and white matter of the adult mouse cerebral cortex. J. Neurosci., 28, 10434-10442.

Doetsch, F. (2003) A niche for adult neural stem cells. Curr. Opin. Genet. Dev., 13, 543-550.

van Dongen, P.A.M. (1998) Ecology, Ethology and Brain Size in Mammals. In Nieuwenhuys, R., Ten Donkelaar, H.J. \& Nicholson, C. (Eds), The Central Nervous System of Vertebrates. Springer, Berlin, Heidelberg, pp. 21162134.

Emsley, J.G., Mitchell, B.D., Kempermann, G. \& Macklis, J.D. (2005) Adult neurogenesis and repair of the adult CNS with neural progenitors, precursors, and stem cells. Prog. Neurobiol., 75, 321-341.

Epp, J.R., Scott, N.A. \& Galea, L.A. (2011) Strain differences in neurogenesis and activation of new neurons in the dentate gyrus in response to spatial learning. Neuroscience, 172, 342-354.

Eriksson, P.S., Perfilieva, E., Bjork-Eriksson, T., Alborn, A.M., Nordborg, C., Peterson, D.A. \& Gage, F.H. (1998) Neurogenesis in the adult human hippocampus. Nat. Med., 4, 1313-1317.

Fischer, I., Konola, J. \& Cochary, E. (1990) Microtubule associated protein (MAP1B) is present in cultured oligodendrocytes and co-localizes with tubulin. J. Neurosci. Res., 27, 112-124. 
Frielingsdorf, H., Schwarz, K., Brundin, P. \& Mohapel, P. (2004) No evidence for new dopaminergic neurons in the adult mammalian substantia nigra. Proc. Natl Acad. Sci. USA, 101, 10177-10182.

Gage, F.H. (2000) Mammalian neural stem cells. Science, 287, 1433-1438.

Garwicz, M., Christensson, M. \& Psounib, E. (2009) A unifying model for timing of walking onset in humans and other mammals. Proc. Natl Acad. Sci. USA, 106, 21889-21893.

Gil-Perotin, S., Duran-Moreno, M., Belzunegui, S., Luquin, M.R. \& GarciaVerdugo, J.M. (2009) Ultrastructure of the subventricular zone in Macaca fascicularis and evidence of a mouse-like migratory stream. J. Comp. Neurol., 514, 533-554.

Gould, E. (2007) How widespread is adult neurogenesis in mammals? Nat. Rev. Neurosci., 8, 481-488.

Gould, E. \& Gross, C.G. (2002) Neurogenesis in adult mammals: some progress and problems. J. Neurosci., 22, 619-623.

Gould, E., Reeves, A.J., Graziano, M.S. \& Gross, C.G. (1999) Neurogenesis in the neocortex of adult primates. Science, 286, 548-552.

Gould, E., Vail, N., Wagers, M. \& Gross, C.G. (2001) Adult-generated hippocampal and neocortical neurons in macaques have a transient existence. Proc. Natl Acad. Sci. USA, 98, 10910-10917.

Grandel, H., Kaslin, J., Ganz, J., Wenzel, I. \& Brand, M. (2006) Neural stem cells and neurogenesis in the adult zebrafish brain: origin, proliferation dynamics, migration and cell fate. Dev. Biol., 295, 263-277.

Grimaldi, P., Parras, C., Guillemot, F., Rossi, F. \& Wassef, M. (2009) Origins and control of the differentiation of inhibitory interneurons and glia in the cerebellum. Dev. Biol., 328, 422-433.

Gritti, A., Bonfanti, L., Doetsch, F., Caille, I., Alvarez-Buylla, A., Lim, D.A., Galli, R., Verdugo, J.M., Herrera, D.G. \& Vescovi, A.L. (2002) Multipotent neural stem cells reside into the rostral extension and olfactory bulb of adult rodents. J. Neurosci., 22, 437-445.

Guillemot, F. (2007) Cell fate specification in the mammalian telencephalon. Prog. Neurobiol., 83, 37-52.

Guo, F., Maeda, Y., Ma, J., Xu, J., Horiuchi, M., Miers, L., Vaccarino, F. \& Pleasure, D. (2010) Pyramidal neurons are generated from oligodendroglial progenitor cells in adult piriform cortex. J. Neurosci., 30, 12036-12049.

Horner, P.J., Power, A.E., Kempermann, G., Kuhn, H.G., Palmer, T.D., Winkler, J., Thal, L.J. \& Gage, F.H. (2000) Proliferation and differentiation of progenitor cells throughout the intact adult rat spinal cord. J. Neurosci., 20, 2218-2228.

Horner, P.J., Thallmair, M. \& Gage, F.H. (2002) Defining the NG2-expressing cell of the adult CNS. J. Neurocytol., 31, 469-480.

Imayoshi, I., Sakamoto, M., Ohtsuka, T., Takao, K., Miyakawa, T., Yamaguchi, M., Mori, K., Ikeda, T., Itohara, S. \& Kageyama, R. (2008) Roles of continuous neurogenesis in the structural and functional integrity of the adult forebrain. Nat. Neurosci., 11, 1153-1161.

Jankovski, A. \& Sotelo, C. (1996) Subventricular zone-olfactory bulb migratory pathway in the adult mouse: cellular composition and specificity as determined by heterochronic and heterotopic transplantation. J. Comp. Neurol., 371, 376-396.

Johnson, K.M., Boonstra, R. \& Wojtowicz, J.M. (2010) Hippocampal neurogenesis in food-storing red squirrels: the impact of age and spatial 
behavior. Genes Brain Behav., 9, 583-591.

Kang, S.H., Fukaya, M., Yang, J.K., Rothstein, J.D. \& Bergles, D.E. (2010) NG2+ CNS glial progenitors remain committed to the oligodendrocyte lineage in postnatal life and following neurodegeneration. Neuron, 68, 668681.

Kaplan, M.S. (1981) Neurogenesis in the 3-month-old rat visual cortex. J. Comp. Neurol., 195, 323-338.

Kaplan, M.S. (2001) Environment complexity stimulates visual cortex neurogenesis: death of a dogma and a research career. Trends Neurosci., 24, 617-620.

Kempermann, G., Gast, D., Kronenberg, G., Yamaguchi, M. \& Gage, F.H. (2003) Early determination and long-term persistence of adult-generated new neurons in the hippocampus of mice. Development, 130, 391-399.

Kempermann, G., Wiskott, L. \& Gage, F.H. (2004) Functional significance of adult neurogenesis. Curr. Opin. Neurobiol., 14, 186-191.

Kempermann, G., Chesler, E.J., Lu, L., Williams, R.W. \& Gage, F.H. (2006) Natural variation and genetic covariance in adult hippocampal neurogenesis. Proc. Natl Acad. Sci. USA, 103, 780-785.

Koketsu, D., Mikami, A., Miyamoto, Y. \& Hisatsune, T. (2003) Nonrenewal of neurons in the cerebral neocortex of adult macaque monkeys. J. Neurosci., 23, 937-942.

Kokoeva, M.V., Yin, H. \& Flier, J.S. (2005) Neurogenesis in the hypothalamus of adult mice: potential role in energy balance. Science, 310, 679-683.

Kokoeva, M.V., Yin, H. \& Flier, J.S. (2007) Evidence for constitutive neural cell proliferation in the adult murine hypothalamus. J. Comp. Neurol., 505, 209220.

Komuro, H., Yacubova, E., Yacubova, E. \& Rakic, P. (2001) Mode and tempo of tangential cell migration in the cerebellar external granular layer. J. Neurosci., 21, 527-540.

Kornack, D.R. \& Rakic, P. (2001) Cell proliferation without neurogenesis in adult primate neocortex. Science, 294, 2127-2130.

Kriegstein, A. \& Alvarez-Buylla, A. (2009) The glial nature of embryonic and adult neural stem cells. Annu. Rev. Neurosci., 32, 149-184.

Kuhn, G.H. \& Blomgren, K. (2011) Developmental dysregulation of adult neurogenesis. Eur. J. Neurosci., 33, 1115-1122.

Laywell, E.D., Rakic, P., Kukekov, V.G., Holland, E.C. \& Steindler, D.A. (2000) Identification of a multipotent astrocytic stem cell in the immature and adult mouse brain. Proc. Natl Acad. Sci. USA, 97, 13883-13888.

Leto, K., Bartolini, A., Yanagawa, Y., Obata, K., Magrassi, L., Schilling, K. \& Rossi, F. (2009) Laminar fate and phenotype specification of cerebellar GABAergic interneurons. J. Neurosci., 29, 7079-7091.

Levison, S.W. \& Goldman, J.E. (1993) Both oligodendrocytes and astrocytes develop from progenitors in the subventricular zone of postnatal rat forebrain. Neuron, 10, 201-212.

Lie, D.C., Dziewczapolski, G., Willhoite, A.R., Kaspar, B.K., Shults, C.W. \& Gage, F.H. (2002) The adult substantia nigra contains progenitor cells with neurogenic potential. J. Neurosci., 22, 6639-6649.

Lindsey, B.W. \& Tropepe, V. (2006) A comparative framework for understanding the biological principles of adult neurogenesis. Prog. Neurobiol., 80, 281-307.

Liu, F., You, Y., Li, X., Ma, T., Nie, Y., Wei, B., Li, T., Lin, H. \& Yang, Z. (2009) 
Brain injury does not alter the intrinsic differentiation potential of adult neuroblasts. J. Neurosci., 29, 5075-5087.

Lledo, P.M., Alonso, M. \& Grubb, M.S. (2006) Adult neurogenesis and functional plasticity in neuronal circuits. Nat. Rev. Neurosci., 7, 179-193.

Lois, C. \& Alvarez-Buylla, A. (1994) Long-distance neuronal migration in the adult mammalian brain. Science, 264, 1145-1148.

Lois, C., García-Verdugo, J.M. \& Alvarez-Buylla, A. (1996) Chain migration of neuronal precursors. Science, 271, 978-981.

Luo, J., Daniels, S.B., Lennington, J.B., Notti, R.Q. \& Conover, J.C. (2006) The aging neurogenic subventricular zone. Aging Cell, 5, 139-152.

Luzzati, F., Peretto, P., Aimar, P., Ponti, G., Fasolo, A. \& Bonfanti, L. (2003) Glia-independent chains of neuroblasts through the subcortical parenchyma of the adult rabbit brain. Proc. Natl Acad. Sci. USA, 100, 13036-13041.

Luzzati, F., De Marchis, S., Fasolo, A. \& Peretto, P. (2006) Neurogenesis in the caudate nucleus of the adult rabbit. J. Neurosci., 26, 609-621.

Luzzati, F., Fasolo, A. \& Peretto, P. (2011) Combining confocal laser scanning microscopy with serial section reconstruction in the study of adult neurogenesis. Front. Neurosci., 5, 70.

Ma, D., Chow, S., Obrocka, M., Connors, T. \& Fischer, I. (1999) Induction of microtubulo-associated protein 1B expression in Schwann cells during nerve regeneration. Brain Res., 823, 141-153.

Magavi, S.S., Leavitt, B.R. \& Macklis, J.D. (2000) Induction of neurogenesis in the neocortex of adult mice. Nature, 405, 951-955.

Maricich, S.M. \& Herrup, K. (1999) Pax-2 expression defines a subset of GABAergic interneurons and their precursors in the developing murine cerebellum. J. Neurobiol., 41, 281-294.

Matsuzaki, K., Katakura, M., Hara, T., Li, G., Hashimoto, M. \& Shido, O. (2009) Proliferation of neuronal progenitor cells and neuronal differentiation in the hypothalamus are enhanced in heat-acclimated rats. Pflugers Arch., 458, 661-673.

McFarland, W.L., Morgane, P.J. \& Jacobs, M.S. (1969) Ventricular system of the brain of the dolphin, Tursiops truncatus, with comparative anatomical observations and relations to brain specializations. J. Comp. Neurol., 135, 275-368.

Migaud, M., Batailler, M., Segura, S., Duittoz, A., Franceschini, I. \& Pillon, D. (2010) Emerging new sites for adult neurogenesis in the mammalian brain: a comparative study between the hypothalamus and the classical neurogenic zones. Eur. J. Neurosci., 32, 2042-2052.

Mirzadeh, Z., Merkle, F.T., Soriano-Navarro, M., Garcia-Verdugo, J.M. \& Alvarez-Buylla, A. (2008) Neural stem cells confer unique pinwheel architecture to the ventricular surface in neurogenic regions of the adult brain. Cell Stem Cell, 3, 265-278.

Mladinic, M., Muller, K.J. \& Nicholls, J.G. (2009) Central nervous system regeneration: from leech to opossum. J. Physiol., 587, 2775-2782.

Nacher, J., Crespo, C. \& McEwen, B.S. (2001) Doublecortin expression in the adult rat telencephalon. Eur. J. Neurosci., 14, 629-644.

Nait-Oumesmar, B., Picard-Riera, N., Kerninon, C., Decker, L., Seilhean, D., Hoglinger, G.U., Hirsch, E.C., Reynolds, R. \& Baron-Van Evercooren, A. (2007) Activation of the subventricular zone in multiple sclerosis: evidence for early glial progenitors. Proc. Natl Acad. Sci. USA, 104, 4694-4699.

Nakatomi, H., Kuriu, T., Okabe, S., Yamamoto, S., Hatano, O., Kawahara, N., 
Tamura, A., Kirino, T. \& Nakafuku, M. (2002) Regeneration of hippocampal pyramidal neurons after ischemic brain injury by recruitment of endogenous neural progenitors. Cell, 110, 429-441.

Nguyen-Ba-Charvet, K.T., Picard-Riera, N., Tessier-Lavigne, M., Baron-Van Evercooren, A., Sotelo, C. \& Chédotal, A. (2004) Multiple roles for slits in the control of cell migration in the rostral migratory stream. J. Neurosci., 24, 1497-1506.

Nishiyama, A., Komitova, M., Suzuki, R. \& Zhu, X. (2009) Polydendrocytes (NG2 cells): multifunctional cells with lineage plasticity. Nat. Rev. Neurosci., $10,9-22$.

Nothias, F., Fischer, I., Murray, M., Mirman, S. \& Vincent, J.D. (1996) Expression of a phosphorylated isoform of MAP1B is maintained in adult central nervous system areas that retain capacity for structural plasticity. J. Comp. Neurol., 368, 317-334.

Nowakowski, R.S. \& Hayes, N.L. (2000) New neurons: extraordinary evidence or extraordinary conclusion? Science, 288(5467), 771.

Ohira, K., Furuta, T., Hioki, H., Nakamura, K.C., Kuramoto, E., Tanaka, Y., Funatsu, N., Shimizu, K., Oishi, T., Hayashi, M., Miyakawa, T., Kaneko, T. \& Nakamura, S. (2010) Ischemia-induced neurogenesis of neocortical layer 1 progenitor cells. Nat. Neurosci., 13, 173-179.

Palmer, T.D., Ray, J. \& Gage, F.H. (1995) FGF-2-reponsive neuronal progenitors reside in proliferative and quiescent regions of the adult rodent brain. Mol. Cell. Neurosci., 6, 474-486.

Palmer, T.D., Markakis, E.A., Willhoite, A.R., Safar, F. \& Gage, F.H. (1999) Fibroblast growth factor-2 activates a latent neurogenic program in neural stem cells from diverse regions of the adult CNS. J. Neurosci., 19, 84878497.

Pekcec, A., Lo"scher, W. \& Potschka, H. (2006) Neurogenesis in the adult rat piriform cortex. Neuroreport, 17, 571-574.

Pencea, V., Bingaman, K.D., Wiegand, S.J. \& Luskin, M.B. (2001) Infusion of brain-derived neurotrophic factor into the lateral ventricle of the adult rat leads to new neurons in the parenchyma of the striatum, septum, thalamus, and hypothalamus. J. Neurosci., 21, 6706-6717.

Peretto, P., Merighi, A., Fasolo, A. \& Bonfanti, L. (1997) Glial tubes in the rostral migratory stream of the adult rat. Brain Res. Bull., 42, 9-21.

Peretto, P., Giachino, C., Aimar, P., Fasolo, A. \& Bonfanti, L. (2005) Chain formation and glial tube assembly in the shift from neonatal to adult subventricular zone of the rodent forebrain. J. Comp. Neurol., 487, 407-427.

Pérez-Martı́n, M., Cifuentes, M., Grondona, J.M., Lo' pez-Avalos, M.D., Go' mezPinedo, U., García-Verdugo, J.M. \& Fernández-Llebrez, P. (2010ª) IGF-I stimulates neurogenesis in the hypothalamus of adult rats. Eur. J. Neurosci., 31, 1533-1548.

Petreanu, L. \& Alvarez-Buylla, A. (2002) Maturation and death of adult-born olfactory bulb granule neurons: role of olfaction. J. Neurosci., 22, 61066113.

Picard-Riera, N., Decker, L., Delarasse, C., Goude, K., Nait-Oumesmar, B., Liblau, R., Pham-Dinh, D. \& Evercooren, A.B. (2002) Experimental autoimmune encephalomyelitis mobilizes neural progenitors from the subventricular zone to undergo oligodendrogenesis in adult mice. Proc. Natl. Acad. Sci. USA, 99, 13211-13216.

Pierce, A.A. \& Xu, A.W. (2010) De novo neurogenesis in adult hypothalamus as 
a compensatory mechanism to regulate energy balance. J. Neurosci., 30, 723-730.

Ponti, G., Aimar, P. \& Bonfanti, L. (2006a) Cellular composition and cytoarchitecture of the rabbit subventricular zone (SVZ) and its extensions in the forebrain. J. Comp. Neurol., 498, 491-507.

Ponti, G., Peretto, P. \& Bonfanti, L. (2006b) A subpial, transitory germinal zone forms chains of neuronal precursors in the rabbit cerebellum. Dev. Biol., 294, 168-180.

Ponti, G., Peretto, P. \& Bonfanti, L. (2008) Genesis of neuronal and glial progenitors in the cerebellar cortex of peripuberal and adult rabbits. PloS ONE, 3, e2366.

Ponti, G., Crociara, P., Armentano, M. \& Bonfanti, L. (2010) Adult neurogenesis without germinal layers: the "atypical" cerebellum of rabbits. Arch. Ital. Biol., 148, 147-158.

Quinones-Hinojosa, A., Sanai, N., Soriano-Navarro, M., Gonzalez-Perez, O., Mirzadeh, Z., Gil-Perotin, S., Romero-Rodriguez, R., Berger, M.S., Garcı`aVerdugo, J.M. \& Alvarez-Buylla, A. (2006) Cellular composition and cytoarchitecture of the adult human subventricular zone: a niche of neural stem cells. J. Comp. Neurol., 494, 415-434.

Rakic, P. (2002) Neurogenesis in adult primate neocortex: an evaluation of the evidence. Nat. Rev. Neurosci., 3, 65-71.

Rakic, P. (2006) Neuroscience. No more cortical neurons for you. Science, 313, 928-929.

Reynolds, B.A. \& Weiss, S. (1992) Generation of neurons and astrocytes from isolated cells of the adult mammalian central nervous system. Science, 255, 1707-1710.

Rietze, R., Poulin, P. \& Weiss, S. (2000) Mitotically active cells that generate neurons and astrocytes are present in multiple regions of the adult mouse hippocampus. J. Comp. Neurol., 424, 397-408.

Rivers, L.E., Young, K.M., Rizzi, M., Jamen, F., Psachoulia, K., Wade, A., Kessaris, N. \& Richardson, W.D. (2008) PDGFRA/NG2 glia generate myelinating oligodendrocytes and piriform projection neurons in adult mice. Nat. Neurosci., 11, 1392-1401.

Robel, S., Berninger, B. \& Gotz, M. (2011) The stem cell potential of glia: lessons from reactive gliosis. Nat. Rev. Neurosci., 12, 88-104.

Rodriguez-Perez, L.M., Perez-Martin, M., Jimenez, A.J. \& Fernandez-Llebrez, P. (2003) Immunocytochemical characterization of the wall of the bovine ventricle. Cell Tissue Res., 314, 325-335.

Sanai, N., Tramontin, A.D., Quinones-Hinojosa, A., Barbaro, N.M., Gupta, N., Kunwar, S., Lawton, M.T., McDermott, M.W., Parsa, A.T., Manuel-Garcia Verdugo, J., Berger, M.S. \& Alvarez-Buylla, A. (2004) Unique astrocyte ribbon in adult human brain contains neural stem cells but lacks chain migration. Nature, 427, 740-744.

Sanai, N., Berger, M.S., Garcia-Verdugo, J.M. \& Alvarez-Buylla, A. (2007) Comment on "Human neuroblasts migrate to the olfactory bulb via a lateral ventricular extension". Science, 318, 393.

Sanchez-Villagra, M.R. \& Sultan, F. (2001) The cerebellum at birth in therian mammals, with special reference to rodents. Brain Behav. Evol., 59, 101113.

Sawamoto, K., Hirota, Y., Alfaro-Cervello, C., Soriano-Navarro, M., He, X., Hayakawa-Yano, Y., Yamada, M., Hikishima, K., Tabata, H., Iwanami, A., 
Nakajima, K., Toyama, Y., Itoh, T., Alvarez-Buylla, A., Garcia-Verdugo, J.M. \& Okano, H. (2011) Cellular composition and organization of the subventricular zone and rostral migratory stream in the adult and neonatal common marmoset brain. J. Comp. Neurol., 519, 690-713.

Schauwecker, P.E. (2006) Genetic influence on neurogenesis in the dentate gyrus of two strains of adult mice. Brain Res., 1120, 83-92.

Schoenfeld, T.A., McKerracher, L., Obar, R. \& Vallee, R.B. (1989) MAP 1A and MAP 1B are structurally related microtubule associated proteins with distinct developmental patterns in the CNS. J. Neurosci., 9, 1712-1730.

Seri, B., Herrera, D.G., Gritti, A., Ferron, S., Collado, L., Garcı `a-Verdugo, J.M. \& Alvarez-Buylla, A. (2006) Composition and organization of the SCZ:large germinal layer containing neural stem cells in the adult mammalian brain. Cereb. Cortex, 16(Suppl 1), i103-i111.

Shapiro, L.A., Ng, K.L., Zhou, Q.Y. \& Ribak, C.E. (2007) Olfactory enrichment enhances the survival of newly born cortical neurons in adult mice. Neuroreport, 18, 981-985.

Shapiro, L.A., Ng, K., Zhou, Q.Y. \& Ribak, C.E. (2009) Subventricular zonederived, newly generated neurons populate several olfactory and limbic forebrain regions. Epilepsy Behav., 14(Suppl 1), 74-80.

Smart, I. (1961) The subependymal layer of the mouse brain and its cell production as shown by radioautography after thymidine-H3 injection. J. Comp. Neurol., 116, 325-347.

Smart, I.H., Dehay, C., Giroud, P., Berland, M. \& Kennedy, H. (2002) Unique morphological features of the proliferative zones and postmitotic compartents of the neural epithelium giving rise to striate and extrastriate cortex in the monkey. Cereb. Cortex, 12, 37-53.

Snyder, J.S., Choe, J.S., Clifford, M.A., Jeurling, S.I., Hurley, P., Brown, A., Kamhi, J.F. \& Cameron, H.A. (2010) Adult-born hippocampal neurons are more numerous, faster-maturing and more involved in behavior in rats than in mice. J. Neurosci., 29, 14484-14495.

Sohur, U.S., Emsley, J.G., Mitchell, B.D. \& Macklis, J.D. (2006) Adult neurogenesis and cellular brain repair with neural progenitors, precursors and stem cells. Philos. Trans. R. Soc. Lond. B Biol. Sci., 361, 1477-1497.

Tamura, Y., Kataoka, Y., Cui, Y., Takamori, Y., Watanabe, Y. \& Yamada, H. (2007) Multi-directional differentiation of doublecortin- and NG2immunopositive progenitor cells in the adult rat neocortex in vivo. Eur. J. Neurosci., 25, 3489-3498.

Teramoto, T., Qiu, J., Plumier, J.C. \& Moskowitz, M.A. (2003) EGF amplifies the replacement of parvalbumin-expressing striatal interneurons after ischemia. J. Clin. Invest., 111, 1125-1132.

Tripathi, R.B., Rivers, L.E., Young, K.M., Jamen, F. \& Richardson, W.D. (2010) NG2 glia generate new oligodendrocytes but few astrocytes in a murine experimental autoimmune encephalomyelitis model of demyelinating disease. J. Neurosci., 30, 16383-16390.

Trotter, J., Karram, K. \& Nishiyama, A. (2010) NG2 cells: properties, progeny and origin. Brain Res. Rev., 63, 72-82.

Vessal, M. \& Darian-Smith, C. (2010) Adult neurogenesis occurs in primate sensorimotor cortex following cervical dorsal rhizotomy. J. Neurosci., 30, 8613-8623.

Vessal, M., Aycock, A., Garton, M.T., Ciferri, M. \& Darian-Smith, C. (2007) Adult neurogenesis in primate and rodent spinal cord: comparing a cervical 
dorsal rhizotomy with a dorsal column transection. Eur. J. Neurosci., 26, 2777-2794.

Weisheit, G., Gliem, M., Endl, E., Pfeffer, P.L., Busslinger, M. \& Schilling, K. (2006) Postnatal development of the murine cerebellar cortex: formation and early dispersal of basket, stellate and Golgi neurons. Eur. J. Neurosci., 24, 466-478.

Wu, H.Y., Dawson, M.R., Reynolds, R. \& Hardy, R.J. (2001) Expression of QKI proteins and MAP1B identifies actively myelinating oligodendrocytes in adult rat brain. Mol. Cell. Neurosci., 17, 292-302.

$\mathrm{Xu}$, Y., Tamamaki, N., Noda, T., Kimura, K., Itokazu, Y., Matsumoto, N., Dezawa, M. \& Ide, C. (2005) Neurogenesis in the ependymal layer of the adult rat 3rd ventricle. Exp. Neurol., 192, 251-264.

Yamashita, T., Ninomiya, M., Hernández Acosta, P., Garcı'a-Verdugo, J.M., Sunabori, T., Sakaguchi, M., Adachi, K., Kojima, T., Hirota, Y., Kawase,Araki, N., Abe, K., Okano, H. \& Sawamoto, K. (2006) Subventricular zone- derived neuroblasts migrate and differentiate into mature neurons in the poststroke adult striatum. J. Neurosci., 26, 6627-6636.

Yang, H.K., Sundholm-Peters, N.L., Goings, G.E., Walker, A.S., Hyland, K.Szele, F.G. (2004) Distribution of doublecortin expressing cells near the lateral ventricles in the adult mouse brain. J. Neurosci. Res., 76, 282-295.

Zhao, M. \& Janson Lang, A.M. (2009) Bromodeoxyuridine infused into the cerebral ventricle of adult mice labels nigral neurons under physiological conditions - A method to detect newborn nerve cells in regions with a low rate of neurogenesis. J. Neurosci. Methods, 184, 327-331.

Zhao, M., Momma, S., Delfani, K., Carlen, M., Cassidy, R.M., Johansson, C.B., Brismar, H., Shupliakov, O., Frisen, J. \& Janson, A.M. (2003) Evidence for neurogenesis in the adult mammalian substantia nigra. Proc. Natl Acad. Sci. USA, 100, 7925-7930.

Zhao, C., Teng, E.M., Summers, R.G. Jr, Ming, G.L. \& Gage, F.H. (2006) Distinct morphological stages of dentate granule neuron maturation in the adult mouse hippocampus. J. Neurosci., 26, 3-11.

Zhu, X., Bergles, D.E. \& Nishiyama, A. (2008) NG2 cells generate both oligodendrocytes and gray matter astrocytes. Development, 135, 145-157. 
